\title{
A Survey of
}

\section{Medical Diagnostic Imaging Technologies}

V. Heese ${ }^{\dagger}$, N. Gmür, W. Thomlinson

National Synchrotron Light Source

Brookhaven National Laboratory

Upton, New York 11973

October 1991

Research Supported by the

OFFICE OF BASIC ENERGY SCIENCES

\section{NATIONAL SYNCHROTRON LIGHT SOURCE BROOKHA VEN NATTONAL LABORATORY Associated Universities, İnc.}

\section{U.S. DEPARTMENT OF ENERGY \\ WASHINGTON, D.C.}

Under Contract No. DE-AC02-76rH00016

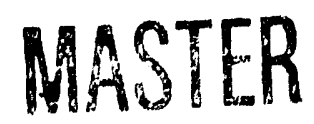




\section{DISCLAIMER}

This report was prepared as an account of work sponsored by an agency of the United States Government. Neither the United States Government nor any agency thereof, nor any of their employees, nor any of their contractors, sub-contractors, or their employees, makes any warranty, expressed or implied, or assumes any legal liability or responsibility for the accuracy, completeness, or usefulness of any information, apparatus, product, or process disclosed, or represents that its use would not infringe privately owned rights. Reference herein to any specific commercial product, process, or service by trade name, trademark, manufacturer, or otherwise, does not necessarily constitute or imply its endorsement, recommendation, or favoring by the United States Government or any agency, contractor or subcontractor thereof. The views and opinions of authors expressed herein do not necessarily state or reflect those of the United States Government or any agency, contractor or subcontractor thereof. 


\section{Table of Contents}

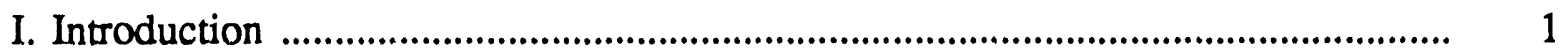

II. Imaging Modalities ….................................................................................. 3

- The Whole Body Counter ..................................................................................... 5

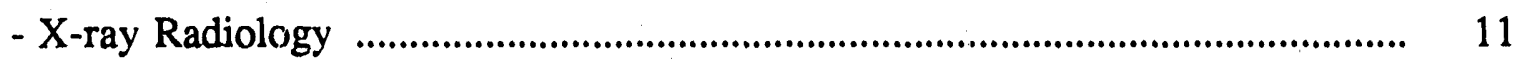

- Conventional Angiography ........................................................................... 17

- Transvenous Angiography ........................................................................................ 23

- Computed Tomography and Multiple Energy Computed Tomography ............ 29

- Ultrasound ................................................................................................... 37

- Nuclear Medicine: PETT, SPECT and Radionuclide Ventriculography ................................................................................ 43

- Magnetic Resonance Imaging ...................................................................... 61

III. Multi-Modality Imaging System ......................................................................... 69

IV. Acknowledgements ..................................................................................... 73

V. Suggested Readings .................................................................................. 75

VI. Key to Imaging Modalities Tables ….............................................................. 79

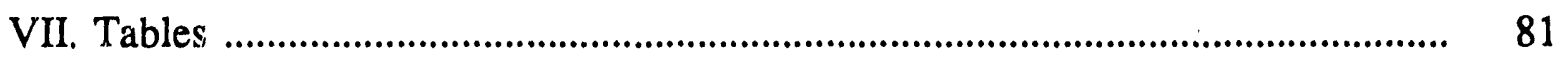




\section{Introduction}

The fields of medical imaging ari medical imaging instrumentation are increasingly important. The state-of-the-art continues to advance at a very rapid pace. In fact, various medical imaging modalities are under development at the National Synchrotron Light Source (such as MECT and Transvenous Angiography.) It is important to understand how these techniques compare with today's more conventional imaging modalities. The purpose of this report is to provide some basic information about the various medical imaging technologies currently in use and their potential developments as a basis for this comparison. This report is by no means an in-depth study of the physics and instrumentation of the various imaging modalities; instead, it is an attempt tc provide an explanation of the physical bases of these techniques and their principal clinical and research capabilities.

The information presented on the various imaging modalities is based partly on discussions with medical specialists who either work at a teaching hospital or at a medical research facility. In consequence, the information thus compiled is reflective of the current state of development of these techniques at the institutions visited.

${ }^{\dagger}$ Present Address: 84 Sunnyside Ave., Westmount, Quebec, H3Y 1C5, Canada. 
$-2-$ 


\section{Imaging Modalities}




\section{The Whole Body Counter}

The term whole body counting (WBC) is in general used for in vivo neutron activation (IVNA) measurements, in which the elemental composition of the body is determined through measurement of the characteristic gamma rays emitted from neutron activated radioisotopes of the elements. Whole body counting provides elemental and consequently compartmental body composition through the analysis of the measured gamma ray spectra.

In these methods, the patient is exposed to a neutron source, which activates, or excites, specific nuclides in the patient's body, depending on the particular WBC technique employed. There are three WBC techniques. The most mature, the delayed gamma neutron activation (DGNA) method activates, among others, ${ }^{48} \mathrm{Ca}$ in the body to the unstable ${ }^{49} \mathrm{Ca}$ nuclide. Total body potassium can be measured from gamma emissions of the natural ${ }^{40} \mathrm{~K}$ content of the body. The prompt gamma neutron activation (PGNA) methor excites ${ }^{14} \mathrm{~N}$ to ${ }^{15} \mathrm{~N}$. Finally, the most recently developed technique, the inelastic neutron scattering (INS) method, employs a deuteron-triton accelerator to produce fast neutrons which excite ${ }^{12} \mathrm{C}$ to its first excited state. All three techniques work on the same principle; the excited nuclei produced by exposure to a neutron source decay and emit gamma rays of a particular energy. The gamma ray energies are analyzed and the resulting WBC spectrum provides information about the elemental composition of the body.

IVNA measurements are usually accompanied by tritiated-water dilution measurement. The patient ingests a small amount $(-50 \mu \mathrm{Ci})$ of tritiated water taken in a glass of orange juice, for example. A small percentage of the hydrogen atoms in tritiated water have been replaced by the tritium atom, which is an isotope of hydrogen containing two neutrons. Several hours later, blood is drawn from the patient and the amount of tritium per unit volume is assayed so the dilution of the tritium atoms in the body of the patient can be determined. The method therefore provides the total body water (TBW). The characteristic TBW of each patient is used to obtain total body hydrogen (TBH). TBH is necessary for calculating total body nitrogen (TBN) from the PGNA measurement method that measures only the relative yield of the nitrogen to hydrogen gamma rays (rather than the absolute yield of the nitrogen gamma rays.) The advantage of the relative measurement is that the errors due to variations in patient body sizes and shapes are to a large extent eliminated.

The WBC technique is not overly risky. No surgical operations are required, and the procedure is performed on an outpatient basis. During this procedure, the patient is exposed to relatively low amounts of ionizing radiation. It is important to note that the radiation produced by a neutron source has a much higher RBE (relative biological effectiveness) than $x$-ray radiation. The RBE of neutrons is ten times more severe than that of $\mathrm{x}$-rays, and for this reason, the WBC technique is not performed on pregnant women, and only rarely on women of childbearing age. 
The utility of the WBC is primarily confined to the field of research. It is a useful technique for studying the amounts of certain key elements in the body. In particular, the DGNA is an ideal technique for monitoring total body bone in postmenopausal osteoperosis research. It is also ideally suited for pharmaceutical companies' research programs to determine the conditions under which dietary supplements, such as potassium, are best absorbed.

In summation, the WBC is a technique that is not suited or practical for everyday diagnosis. Relatively few facilities of this sort exist worldwide. Instead, it is best suited to serve as a medical standard facility by which new medical treatments can be evaluated through studies. It provides the only means of direct measurement of the elemental makeup of the human body. 


\section{Medical Imaging Technologies Survey}

The Whole Body Counter

i) = Delayed Gamma method (DGNA)

ii) = Prompt Gamma method (PGNA)

iii) $=$ Inelastic neutron scattering method (INS)

SYSTEMS IMAGED/MEASURED: Whole body (elemental analysis)

FORM OF INFORMATION:

QUALITY OF INFORMATION:

RESOLUTION:

SPATIAL RESOLUTION:

TEMPORAL RESOLUTION:

ELEMENTAL RESOLUTION:

NON/INVASIVE:

RADIATION EXPOSURE:

IN/OUTPATIENT:

RISK:

MORTALITY:

MORBIDITY:

MATURITY:

AVAחLABITYY:

COST:

WHOLE FACILITY:

PER USE:

UTILITY:
Spectrum of body's elemental composition (not an actual image of body) - see Figure 1

Excellent (accurate analysis of chemical composition of body)

None

Time exposed to neutron source

i) $15 \mathrm{~min}$ ii) $30 \mathrm{~min}$ iii) $30 \mathrm{~min}$

i) $\mathrm{Na}, \mathrm{P}, \mathrm{Cl}, \mathrm{K}, \mathrm{Ca}$ ii) $\mathrm{N}$ iii) $\mathrm{C}$

Noninvasive (tritiated water is ingested)

i) $270 \mathrm{mRem}$

ii) $25 \mathrm{mRem}$

iii) $15 \mathrm{mRem}$

Dutpatient

None

Low (nevertheless this technique is not performed on pregnant women and only rarely on women of childbearing age because of exposure to a neutron source)

i) Mature (20 years)

ii) Mature (12 years)

iii) Experimental (6 -7 years)

Rare (few facilities worldwide)

\$2 million.

$\$ 2400$. (for use of all three facilities)

Primarily research studies 
( )

\section{$-$}




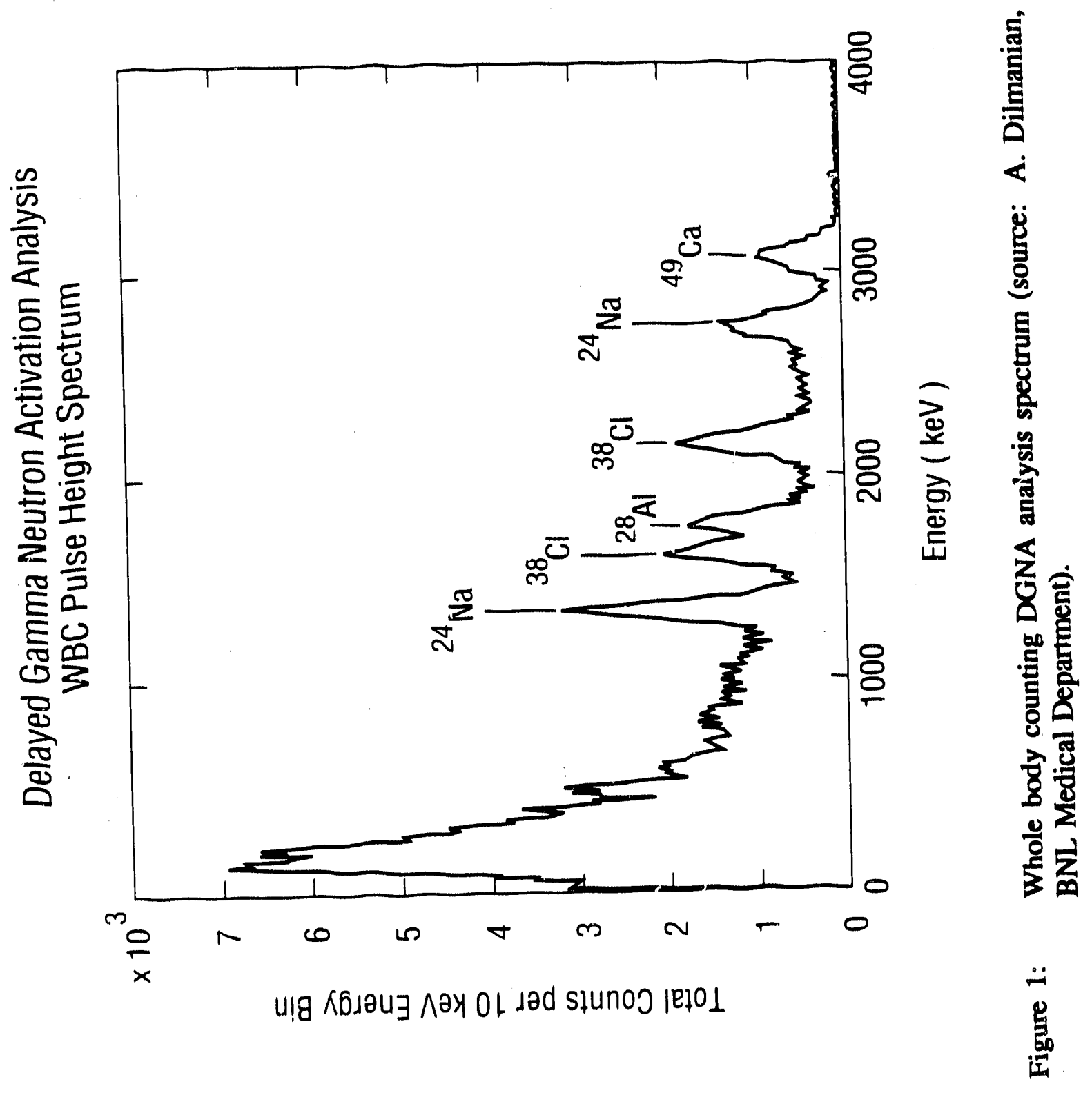


$-10$ 


\section{X-Ray Radiology}

$\mathrm{X}$-ray radiology is the oldest and most common imaging modality in use at present. Even though the technology involved in $x$-ray radiology was first discovered in the late 1800 s, it is a technology that is still of much value today.

$\mathrm{X}$-rays are a form of cadiation that were first noted by the German physicist Wilhelm Conrad Roentgen in 1895 . He discovered them by accident while investigating the behavior of cathode rays, better known today as electrons. He found that this heretofore unknown radiation was produced when the cathode ray tube was energized, and that this radiation displayed a characteristic relationship with matter. These rays were easily transmitted through certain substances but were absorbed by others, and these $\mathrm{x}$-ray transmissions (so named because Roentgen did not understand the nature of this radiation) could leave images on a fliorescent screen.

Today the nature of this radiation is well known. X-rays are a form of electromagnetic radiation that is produced when a fast moving stream of electrons is decelerated. They can be generated when a tungsten or tungsten alloy filament serving as a cathode (negative electrode) is heated with an electric current. This causes a stream of energized eicrtrons to separate from the cathode and be available for acceleration toward the positively charged tungsten anode, a positive electrode. A potential difference between the two electrodes will cause the electron stream to accelerate towards the anode. When this strean strikes the anode, polychromatic $x$-ray radiation is produced. This radiation, which is emitted in discrete pulses (due to the rectification process of alternating current), can be directed toward any part of a patient's body that is to be imaged.

$\mathrm{X}$-rays interact with matter in such a way that increasing the radiation energy by increasing the acceleration potential will increase the transmission of $\mathrm{x}$-rays through matter. Increasing the atomic number, density, or electrons per gram of the irradiated area will decrease the transmission of $\mathrm{x}$-rays. In $\mathrm{x}$-ray imaging, those $\mathrm{x}$-rays that are transmitted and continue straight through the patient's body strike a fluorescent screen which transforms the $\mathrm{x}$-ray radiation into visible light. This visible light is allowed to expose a piece of photographic film, and so an image representative of the transmission of $\mathrm{x}$-rays through the patient's body can be produced.

The resulting image is darker where there is more transmission and lighter in areas where $x$-rays have been absorbed. As a result, dense structures such as bone absorb much of the beam and appear light while less dense areas such as the air-filled lungs produce very little absorption and appear quite dark. In conventional $x$-ray imaging, shadows occur from overlapping organs because density information (as revealed by the $\mathrm{x}$-ray beam) is collected from only one direction. In consequence, images of such soft tissue areas as the abdomen are characterized by the superposition of the images of the different structures in the abdominal cavity, making an accurate examination of these structures difficult. 
Contrast agents are sometimes used in $\mathrm{x}$-ray radiology to improve the picture contrast during such soft tissue imaging studies. Soft tissues have similar densities and so are not well differentiated during conventional $x$-ray studies. Barium and iodine salts are used to improve this differentiation, since they strongly absorb the incoming $x$ rays. Barium can be ingested to improve gastrointestinal examinations, and iodine can be injected or internally administered by catheter to aid the results of vascular or urinary system studies. In this way, the contrast-filled structures will appear well defined in relation to the otherwise comparably dense structures in their vicinity.

In conventional $x$-ray imaging, it is possible that some rays passing through the patient's body are deflected and not absorbed by the dense structures in the body. In this case, the resulting image becomes blurred, and is not exactly representative of bodily structures. To counteract this scattering effect, a fine grid made of lead and wood strips can be placed between the patient and the fluorescent screen. This grid absorbs the scattered $x$-rays and allows the undeflected rays to continue straight through and strike the screen.

Because conventional $x$-ray imaging is the most mature imaging technique in common use at present, this long standing, basic technology has contributed to many advances in the field of human diagnostic imaging which have applications to other more recent imaging technologies. In particular, $x$-ray radiology has formed the basis for such techniquer $\approx$ Ansuscopy and tomography, which are techniques that are applicable to other imaging modalities.

Fluoroscopy is an imaging technique which allows the display of the human body in real time on a television monitor. In this technique, a continuously generated $x$-ray beam is directed at the patient's body. The continually transmitted $x$-rays are detected by an image intensifier which is an instantaneous photon conversion and amplification device, and the pattern of the x-rays is converted to an electronic signal which can be displayed as a television image. The resulting fluoroscopic image can be recorded by a cine camera or in digital format on magnetic tape. The fluoroscopic technique allows the opportunity to monitor and record, in vivo, the progress of a contrast agent injected into or ingested by the patient for a particular technique such as conventional arterial angiography.

Tomography is another imaging technique which has its roo's in $x$-ray radiology but now has broad applications and plays a part in other imaging 1nodalities. Tomography is the process whereby a particular structure or plane of intere:t in the patient's body can be imaged without the interference of overlying or underlying structures, as is the case in conventional $x$-ray imaging. This process, as developed in $x$-ray radiology, involves an $x$-ray tube source and an $x$-ray film cassette detector (containing a fluorescent screen and photographic film) which move about a pivot point in the body. In consequence, tomography allows the clear definition of specific structures lying deep within the human body. 


\section{Medical Imaging Technologies Survey}

\section{X-Ray Radiology}

SYSTEMS IMAGED:

Skeletal and organ systems (general diagnostic radiology)

FORM OF IMAGE:

Planar projection (any axis) - see Figure 2

QUALITY OF IMAGE:

Good to Excellent

RESOLUTION:

SPATIAL RESOLUTION: $\quad 0.2 \mathrm{~mm}$

TEMPORAL RESOLUTION: $\quad 1 / 120 \mathrm{sec}$ per $\mathrm{x}$-ray pulse

Exposure times vary from $1 / 60 \mathrm{sec}$ for chest area to $1 / 2 \mathrm{sec}$ for a spinal study

ELEMENTAL RESOLUTION: None

NON/INVASIVE:

Noninvasive

RADIATION EXPOSURE:

$8 \mathrm{mR}$ (for chest) - 300 $\mathrm{mR}$ (for spinal study)

Exposure is strictly limited to area imaged

IN/OUTPATIENT:

Outpatient

RISK:

MORTALITY:

None

MORBIDITY:

Low (nevertheless, this technique is not readily performed on pregnant women because of potential somatic and genetic effects of ionizing radiation)

MATURITY:

Mature (technology is about 95 years old)

AVAILABILITY:

Very common (found in all hospitals)

COST:

WHOLE FACILITY:

PER USE:

UTILITY:
$\$ 47,000 .-\$ 125,000$.

$-\$ 75$.

Routine clinical diagnostic imaging. 
$-14$ 


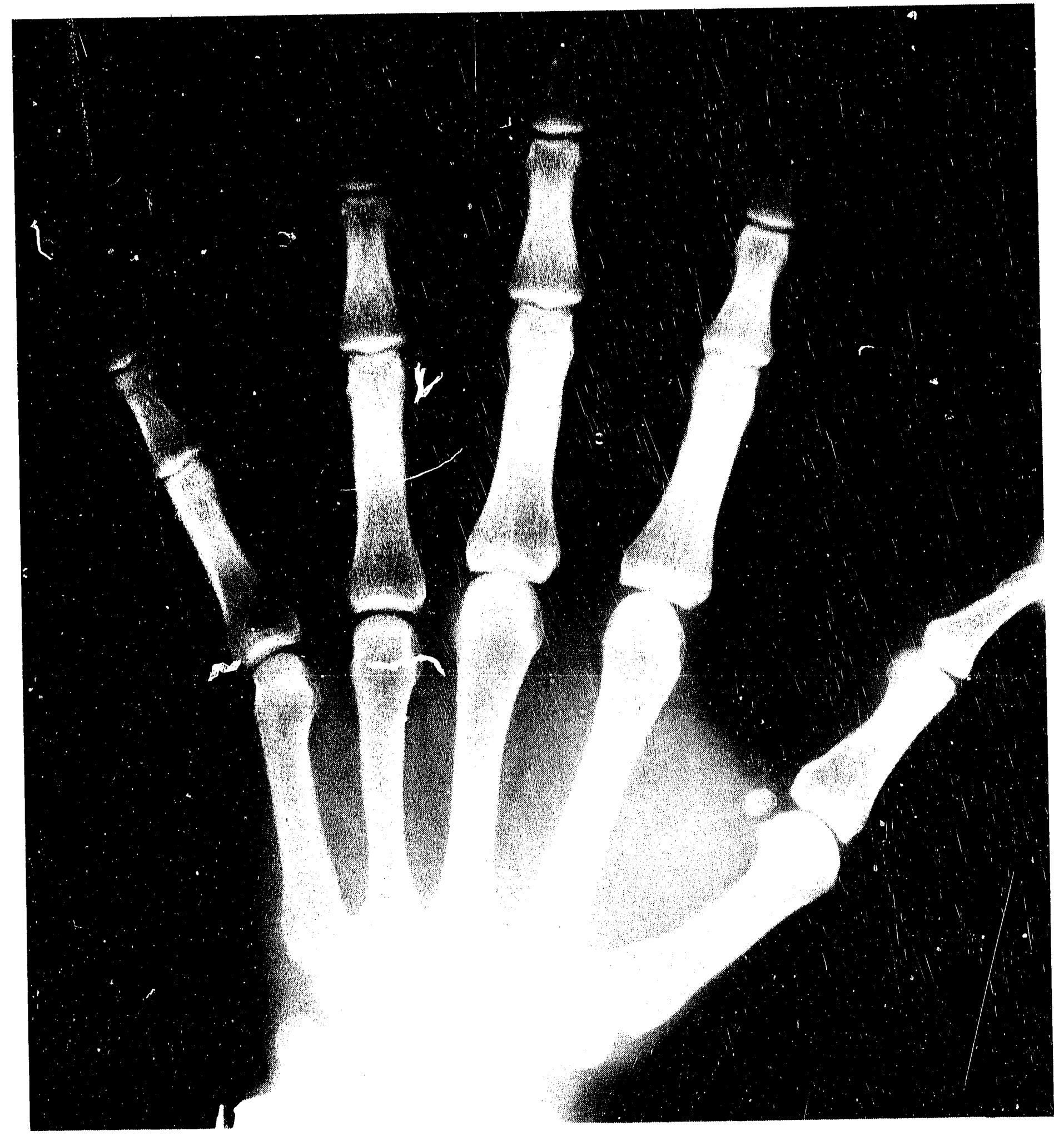

Figure 2: Conventional X-ray image of left hand (source: W. Lehman, BNL Medical Department). 


\section{Conventional (Arterial) Angiography}

Heart disease is one of man's primary medical concerns. Coronary artery disease progresses as fatty deposits, known as plaque, build up in the arteries of the heart. If more than about $20-30 \%$ of the lumen (the cavity or channel within a tube or tubular organ such as a blood vessel) of a coronary artery is obstructed, the plaque surface may rupture, causing a blood clot to form which can restrict or even stop the flow of blood in the artery. The resulting injury or death to heart muscle tissue due to lack of oxygen gives rise to the common symptoms (such as pain and shortness of breath) of a heart attack.

Conventional angiography is, at present, the most common way to accurately image and consequently diagnose the state of the coronary arteries - up to $30 \%$ of all hospitals in the U.S. are equipped to perform this cinefluoroscopic technique. In this procedure, a catheter is threaded into either the femoral artery (which is the faster approach) or into the subclavian artery (an approach which is more tedious for the doctor but ultimately safer for the patient) and is manipulated to the neck of the high pressure aorta and into the specific coronary artery to be imaged. Once in place, a contrast agent (which is more opaque to $x$-rays than normal body tissues) such as iodine is injected from the tip of the catheter into the artery, and any lesions or plaque-induced blockages are clearly evidenced on the real time $35 \mathrm{~mm}$ cinefilm recording of the resulting $\mathrm{x}$-ray images.

One advantage of this procedure is that, if necessary, balloon angioplasty can be performed in conjunction with this imaging technique. In this case, a second, smaller catheter is inserted and is threaded to the site of blockage. This second catheter has a special 'balloon' attachment which can be inflated to push aside plaque deposits and effectively clear thi passageway, allowing the blood to flow through freely. However, it should be noted that plaque build-up recurs in $-40 \%$ of the cases on a time scale of six montns.

Conventional angiography is not without risk. For instance, the catheter itself can damage the arterial wall. Secondly, there exists the possibility that the catheter may dislodge some plaque, allowing fragments of the fatty deposits to escape into the bloodstream. These fragments can trigger cardiac arrest in the heart itself, or can cause much damage to major organs if allowed to circulate in the body. For instance, bits of plaque that reach the brain can induce stroke, and renal damage can occur if these fragments reach the kidneys. The patient may actually lose the use of a limb due to nerve damage.

It is possible for this procedure to induce an allergic reaction or cardiac arrest when the dye momentarily replaces coronary artery blood during its injection for the imaging. In addition, the patient is exposed to a fairly high radiation dose during this fluoroscopic procedure since the patient is exposed to a continuously generated $\mathbf{x}$-ray source. Radiation dose varies from 15 to 30 rads, with the average dose being approximately 22 rads. 
Thus, conventional angiography is not utilized for routine screening of patients or research projects due to the significant risk involved in its application. Although conventional angiography poses considerable risk to the patient, the images produced by this technique are of such excellent quality and diagnostic value that in many cases, the benefits far outweigh the risks. 


\section{Medical Imaging Technologies Survey}

\section{Conventional (Arterial) Angiography}

SYSTEMS IMAGED:

FORM OF IMAGE:

QUALITY OF IMAGE:

RESOLUTION:

SPATIAL RESOLUTION:

TEMPORAL RESOLUTION:

ELEMENTAL RESOLUTION:

NON/INVASIVE:

RADIATION EXPOSURE:

IN/OUTPATIENT:

RISK:

$$
\text { MORTALITY: }
$$

MORBIDITY:

MATURITY:

AVAILABILITY:

COST:

WHOLE FACILITY:

PER USE:

UTILITY:
Heart (coronary arteries)

Planar projection - see Figure 3

Excellent (easy diagnosis)

$0.5 \mathrm{~mm}$

45 frames $/ \mathrm{sec}(-22 \mathrm{msec} /$ frame $)$

None

Invasive (requires arterial catheter)

Between 15-30 rads

Average: 22 rads

Inpatient (usually from 1 - 3 days' stay)

$0.01 \%$

$0.1 \%-1 \%$

Mature (approximately 25 years)

Fairly common (30\% of hospitals have such facilities)

$\$ 1.5$ million.

$\$ 2200$. for procedure

$\$ 5200$. including hospital stay and laboratory fees

Clinical use (diagnosis of state of coronary arteries)

Angioplasty may be performed in conjunction with this technique 


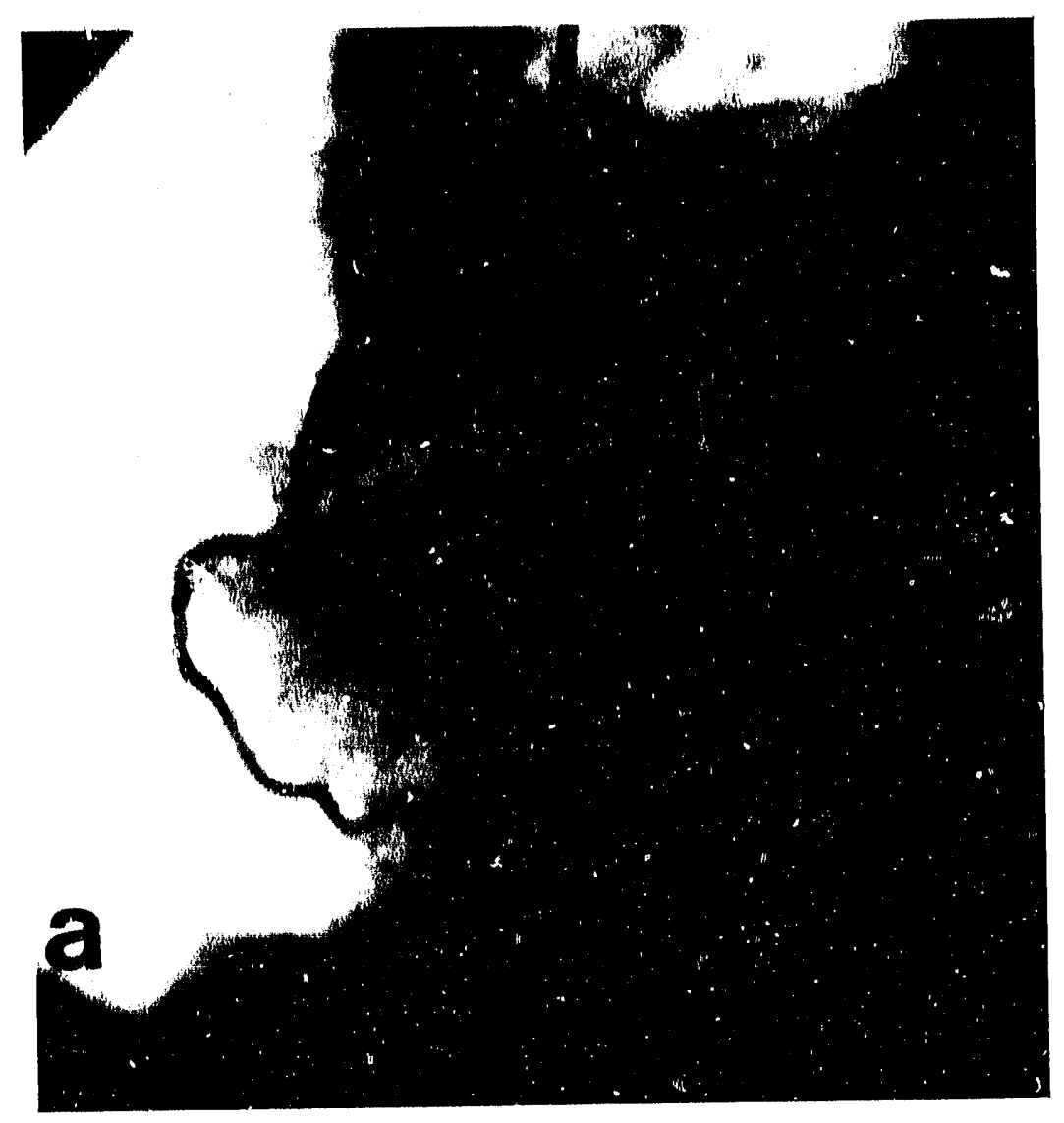

Figure 3: Conventional arterial coronary angiogram (left anterior oblique view $45^{\circ}$ ); single frame of cinefluoroscopic procedure (source: J. Morrison, North Shore University Hospital). 


\section{Transvenous Angiography}

The Synchrotron Medical Research Facility (SMERF) at the National Synchrotron Light Source (NSLS) is the first medical installation in the world to use electromagnetic synchrotron radiation to image and diagnose the state of human coronary arteries. The principle of this technique is similar to that of conventional arterial angiography, in that a contrast agent is injected to enharice visualization of the coronary system on the resulting $x$-ray image. However, there are several fundamental differences between the two techniques.

Polychromatic or bremsstrahlung $\mathrm{x}$-ray radiation, which is produced by the deceleration of electrons on a metal surface, is used in conventional angiography. The $x$-rays thus produced are emitted in a broad band spectrum and are of relatively low intensity. The broad spectrum of $x$-ray radiation to which the patient is exposed is not all necessary for imaging with the iodine contrast agent.

In contrast, the $x$-ray radiation used in transvenous angiography at SMERF is synchrotron radiation, which is radiation emitted by a charged particle as it is accelerated in a magnetic field. The synchrotron radiation produced at the NSLS is a high intensity broad energy spectrum which ranges continuously from the infrared to up to 100 $\mathrm{keV} x$-rays. The $\mathrm{x}$-ray radiation produced at this facility is from $10^{2}$ to $10^{5}$ times more intense than conventional $\mathrm{x}$-rays at comparable $\mathrm{x}$-ray energies. $\mathrm{X}$-rays not necessary for the imaging study being performed can be filtered out by monochromators. The remaining $\mathrm{x}$-rays are intense enough to allow fast data acquisition and the production of images comparable in spatial resolution to those produced by conventional angiography.

The k-edge of a particular element is defined as the energy of $\mathrm{x}$-ray radiation to which an atom of this element must be exposed for an electron in the innermost kshell to be ejected from the atom. In terms of $x$-ray imaging, the $x$-ray absorption of the contrast agent increases significantly when exposed to $x$-rays of energies greater than its k-edge compared to $x$-rays of lower energy. It should be noted, however, that the absorption of soft tissues and bone remains roughly the same above and below the k-edge of typical contrast agents.

This basic atomic property can be used in the imaging of coronary arteries. At SMERF, two monoenergetic, collimated fan beams of $x$-ray radiation (one beam with energy below the k-edge of the iodinated contrast agent being used and one above) are directed at the patient and converge at the heart. They diverge after the patient and each beam is picked up by a separate detector array, resulting in the production of two simultaneous images. The higher energy image displays the contrast from the iodine dye in the coronary arteries, and the lower energy image does not. The lower energy image is then digitally subtracted from the higher energy image so that the surrounding soft tissues and bone can be eliminated from the final image. As a result, a clear depiction of the contrast agent laden coronary arteries is produced. 
The complete two dimensional image of the heart produced in this technique is made up of 256 stacked line images and is acquired in -1 second. Each line image is produced in 4 milliseconds, which is fast enough to effectively eliminate any motional artifacts from the beating of the heart. The different phases of the patient's cardiac cycle (as recorded by an electrocardiogram) can be correlated to the final image.

The 'tunability' of the $\mathrm{x}$-ray radiation used in this technique also allows a variety of contrast agents to be considered for the procedure, since beam energies suitable for the k-edge of a desired contrast agent can be selected. Nevertheless, iodine, whose $k$ edge is at $33.16 \mathrm{keV}$, is still the most commonly used agent.

The intensity of the synchrotron generated $x$-rays and the k-edge subtraction technique allow the injected contrast agent to be more dilute than in conventional angiograpiry. In consequence, the contrast agent is administered via a venous catheter, (as opposed to the arterial catheter used in conventional angiography), so the contrast agent is diluted 30-40 fold in the blood before it reaches the heart's arterial system. The venous approach eliminates most of the risks associated with the arterial injection, such as the risk of dislodging plaque in the high pressure coronary arteries, arterial hemorrhage, and the displacement of blood from the arteries.

Finally, no hospital stay is required for the transvenous angiography procedure. Consequently, it is hoped that the technique, though still in its experimental stages, will contribute to the research and development of drugs for patients recovering from heart attack, and may someday even become a viable alternative to comparatively high risk conventional angiography. 


\section{Medical Imaging Technologies Survey}

\section{Transvenous Angiography at SMERF}

SYSTEMS IMAGED:

FORM OF IMAGE:

QUALITY OF IMAGE:

RESOLUTION:

SPATIAL RESOLUTION:

TEMPORAL RESOLUTION:

ELEMENTAL RESOLUTION:

NON/INVASIVE:

RADIATION EXPOSURE:

IN/OUTPATIENT:

RISK:

MORTALITY:

MORBIDITY:

MATURITY:

AVAILABILITY:

COST:

WHOLE FACILITY:

PER USE:

UTILITY:
Heart (coronary arteries)

Planar projection - see Figure 4

Excellent

$0.5 \mathrm{~mm}$

$4 \mathrm{msec} / \mathrm{line}$

Iodinated contrast agents

Invasive (venous catheter)

20 rads

Outpatient

Low

Low (allergic reaction possible)

Experimental ( $\sim 5$ years)

Research at NSLS, HASYLAB and Photon Factory

$\$ 2$ million (for beamline at a synchrotron facility)

Experimental only

Validation of imaging technique at present Clinical research phase in $1-2$ years 


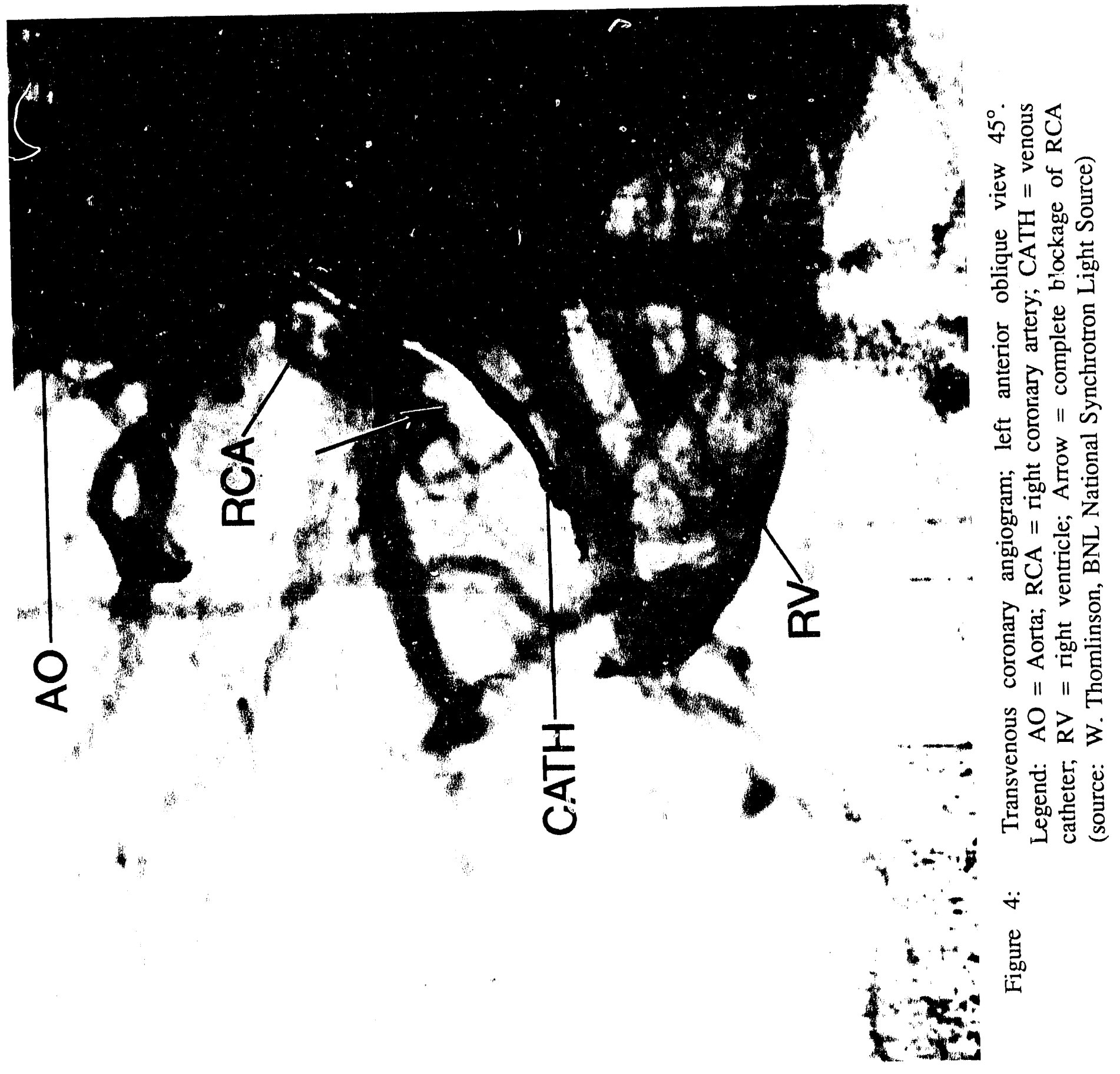




\section{Computed Tomography and Multiple Energy Computed Tomography}

Computed tomography (CT) is based on the same physical principles as conventional $x$-ray radiology, in that $x$-ray radiation is either absorbed or transmitted to different degrees by bodily structures of different densities. However, CT scanning has proven to be a far more advanced technique than conventional $x$-ray imaging since it can depict, to a much more precise degree, the radiographic density differences between tissues, mainly due to the high-speed digital calculation capabilities of modern computers as well as generating planar views through "slices" of the human anatomy.

A CT image is compiled by the digital integration of multiple $x$-ray projections produced by an $x$-ray source and detector combination travelling in a circular path about a patient. Because the cross-sectional portion of the body being examined is imaged through $360^{\circ}$, no shadowing occurs in this technique and underlying and overlying tissues do not obscure the plane being imaged. The resulting axial tomographic images are accurate representations of internal bodily structures with discernible contrast differences as low as $0.5 \%$.

CT scanning has undergone much development and refinement during the 20 years of its existence, and both third and fourth generation scanners are primarily in use at present. Third generation scanners (or "rotate-rotate" scanners) consist of an arc of detectors mounted opposite from an x-ray tube. The detectors and the x-ray source move simultaneously in a circle around the patient. Fourth generation scanners (or "rotate-fixed" scanners) consist of an immobile ring of detectors around the patient and an $x$-ray tube which rotates about the patient in a circle inside the ring of detectors. Neither generation of scanner is inherently superior to the other, and both scanners produce excellent images with short scan times.

The most common detectors currently employed in CT scanning are xenon high pressure gas detectors. These detectors (used in third generation scanners only) consist of the inert gas xenon sandwiched between an anode and a cathode. X-ray photons entering the xenon gas chamber produce ionization in the gas. The collection of the ion pairs produces a small current, and this current is the cutput signal from the detector. This current is directly proportional to the number of $\mathrm{x}$-ray photons passing through the chamber. However, xenon gas ionization detectors are quite inefficient since not every $\mathrm{x}$-ray photon encounters a gas atom. In consequence, many $\mathrm{x}$-ray photons pass undetected. At present, more and more CT imaging facilities are converting to solid state detectors, which can be used in third or fourth generation scanners. These detectors are more efficient and more stable than xenon detectors.

The creation of an actual CT image requires that the cross-sectional tomographic slice of the body being imaged be divided up into small blocks known as voxels. Each voxel is represented on the final image by a small square called a pixel. The CT image itself is made up of a matrix of these pixels. Each pixel is assigned a particular 
CT number depending on the average tissue density of the corresponding voxel in the body. The CT number, in turn, relates to a certain level of brightness in the grey color scale used in the depiction of a CT image. In this way, 3-D information about the density characteristics of the body can be presented as a 2-D planar image.

Water is assigned a CT value of 0 , while the CT values of air and bone range from -1000 to 1000 . However, CT images cannot be presented in terms of 2001 different shades of grey because the image would be too confusing. In consequence, an enhanced grey scale (consisting of usually about 16 to 20 shades of grey) is used to make the contrast understandable. The grey scale used in this technique can thus be manipulated, so that the window level (the center of the grey scale used) and the window width (the range of the CT numbers above and below this center) are operator selectable. During a typical CT scan, multiple window levels and window widths are implemented so that maximum diagnostic information can be obtained from the exam. Pathogenic or diseased tissues are often characterized by a change in the normal tissue density, and so the CT technique is ideally suited to pinpoint abnormal tissue masses and to reveal the nature of the tissue in these masses. Nevertheless, as in conventional $x$-ray radiology, contrast media such as intravenously administered iodine and ingested barium can be used to even further enhance contrast.

Patient movement is an important consideration in CT imaging. Although the CT scan time is relatively short, (usually on the order of -2 seconds), cardiac studies are not feasible with this technique. Images of the abdomen can also be considerably blurred by the breathing of a patient, and so the patient must hold his/her breath during an abdominal scan. Head studies, on the other hand, are consequently well suited to this technique and thus typically produce extremely good results.

It is worthy to note that the tomographic slices obtained from CT imaging can be digitally 'stacked' so that three dimensional views of a particular organ or structure can be obtained. CT imaging is thus not only one of the most common imaging modalities in use at present (over $95 \%$ of hospitals have such facilities) but it has also proven to be an invaluable and versatile diagnostic tool.

Multiple energy computed tomography (MECT) is another medical diagnostic CT technique under development at SMERF. This technique will use the tunable $x$-rays provided at a synchrotron facility to provide CT images of superior spatial resolution $(0.5 \mathrm{~mm})$. These images also reveal the elemental composition of the tissues imaged. The installation will consist of a fixed, collimated, fan-shaped x-ray beam and a rotating patient chair. Brain tumors, the large blood vessels of the lower head and neck, and arteriovenous malformations will be imaged using the k-edge subtraction technique described previously. In addition, CT images representative of the concentrations of either low- or intermediate-Z elements in the brain will be produced according to the principles of dual photon absorptiometry (DPA). DPA uses two widely separated energies to show the differences between the absorption coefficients of the low- and 
intermediate- $Z$ elements found in the tomographic slice of the brain being imaged. The high energy absorption is characterized by the Compton effect and the low energy absorption is characterized by the photoelectric effect. From this information, two images (each highlighting one of the two groups of elements specified) of the tomographic slice of the brain can be digitally compiled.

The MECT technique is yet another application of synchrotron radiation to the field of medicine. Although this technique is still very much in its experimental stages, it is anticipated that it will sontribute much to the field of medical research and may eventually be clinically useful. 


\section{Medical Imaging Technologies Survey}

\section{Computed Tomography}

SYSTEMS IMAGED:

FORM OF IMAGE:

QUALITY OF IMAGE:

RESOLUTION:

SPATIAL RESOLUTION:

TEMPORAL RESOLUTION:

ELEMENTAL RESOLUTION:

NON/INVASIVE:

RADIATION EXPOSURE:

IN/OUTPATIENT:

RISK:

MORTALITY:

MORBIDITY:

MATURITY:

AVAILABILITY:

COST:

WHOLE FACILITY:

PER USE:

UTILITY:
Whole body

Tomographic axial plane - see Figure 5 (3-D imaging possible)

Excellent

$1 \mathrm{~mm}$

2 seconds

None

Norinvasive

Head studies: 5 rads

Body studies: 2 rads

(Single slice studies: $40 \%$ less than multislice studies)

Outpatient

None

Low (allergic reaction to iodine contrast agent is possible)

Mature ( 20 years)

Common $(-95 \%$ of hospitals have such facilities)

$\$ 500,000$. $\$ 1.2$ million.

$\$ 425$.

Common clinical use 


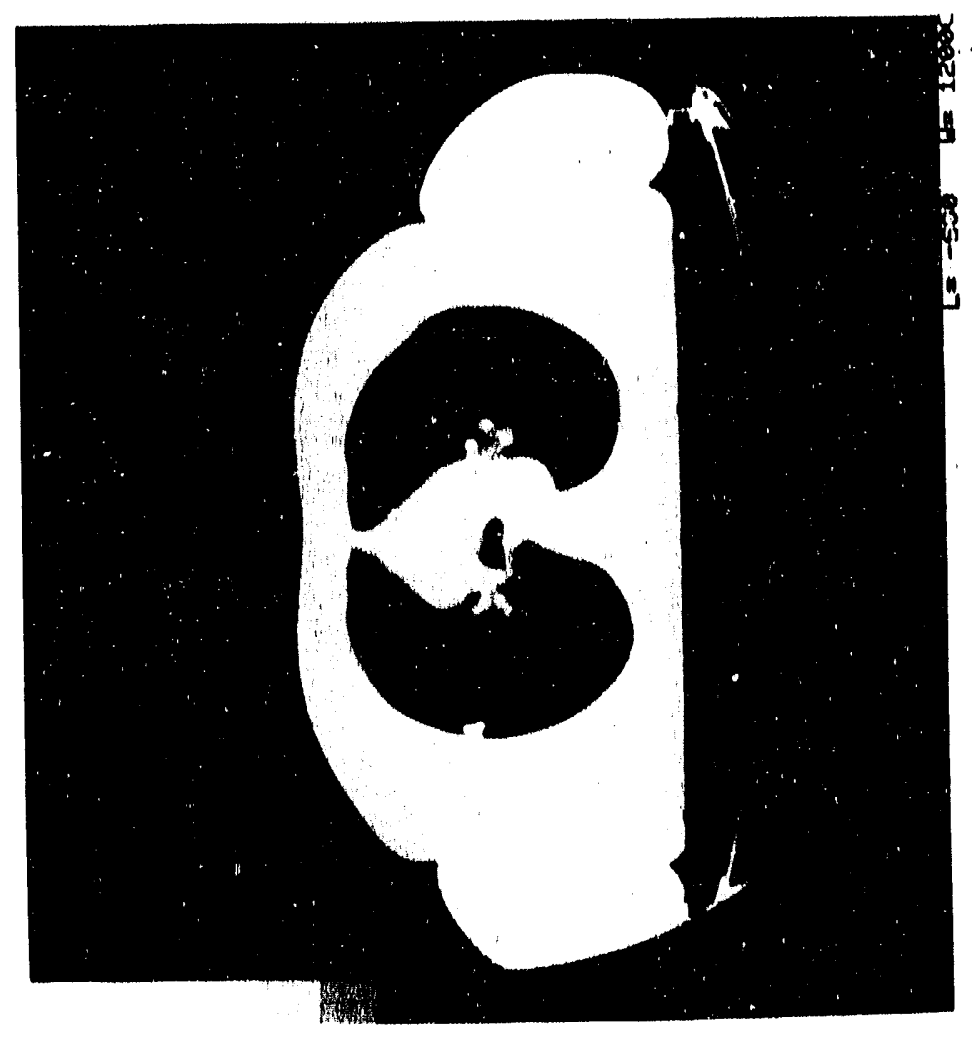

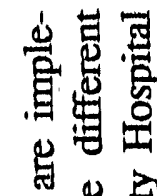

总总

영 9

营焉

I is

葛免

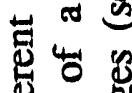

出

焉菌 为 颉夏是 别昰忌 요옹

(c) 专光 명 눙

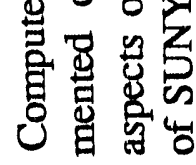

in

狊 


\section{Ultrasound}

Ultrasound imaging (or "sonography") is based on the premise that high frequency sound waves can be transmitted through the tissues of the patient being imaged. Some of this sonic energy is reflected back and is analyzed to reconstruct an image of the internal body structure. Ultrasonic sound waves are defined as having frequencies greater than $20,000 \mathrm{~Hz}$ or cycles per second. The sound waves used for imaging generally have a frequency between $1 \mathrm{MHz}$ and $10 \mathrm{MHz}$.

The sonic energy used in this technique is generated in a transducer which is held in direct contact with the tissues to be imaged. A transducer can be defined as a device which converts one form of energy to another. For ultrasound application, the transducer serves as a converter of electrical signals to sound waves and converts the reflected sound waves back to electrical signals. This is accomplished by means of an array of ceramic piezoelectric crystals contained in the transducer. When a piezoelectric crystal is subjected to a short voltage pulse, the crystal is distorted. In returning to its original shape, the crystal produces a burst of mechanical vibration which generates sound waves. These sound waves are then transmitted into the body and are either reflected, deflected, or absorbed by the different components of the internal structure. The amount of the initial sound wave that is reflected back to the transducer depends on the differences in densities of the various anatomical features of the body. The greater the difference in acoustic impedence (which is density multiplied by the speed of sound) between two adjacent materials, the stronger the reflection.

Air and bone both strongly reflect the sonic signal and so are not good media for the transmission of sound waves, but a fluid medium is ideal for these purposes. As a consequence, ultrasound studies of body regions completely surrounded by bone (such as the head) are difficult. Patients may be required to ingest much fluid prior to abdominal studies so as to eliminate the interference of gas pockets in the bowel in the resulting image.

The reflection or "echo" of the incident sound pulse is detected by the transducer. This reflection also changes the shape of the piezoelectric crystal. This momentary alteration of the crystal's structure is converted, in an exact reversal of the previous process, into an electrical signal. All the electrical signals produced by the transducer are recorded and the time delay of each echo serves as an indicator of depth. All the information collected by the transducer is thus digitally compiled into an image representative of the tissues examined.

The video image produced in this technique is expressed in a grey color scale, with different shades of grey assigned to returning sound waves of varying intensities. The tandem or axial resolution of the image (the ability to resolve trvo objects of different depths) depends on the length of the sonic pulse. The lateral or horizontal resolution (the ability to resolve between two adjacent objects) depends on the width of the sonic pulse and, in general, decreases with increasing distance from the transducer because of the radial nature of the beam at large distances. 
A new ultrasound technique called color Doppler is currently being developed. The Doppler effect is the perceived frequency shift when a sound source moves towards or away from a specific point. This shift is created because the frequency of sound from an approaching source has a shorter wavelength (and thus a higher pitch) than a sound source moving away from the observer. This physical phenomenon can be used to help calculate blood flow in specific parts of the body, because sound waves beamed at a moving interface will reflect back with a different frequency. From the change in frequency between the incident sound waves and the returning echo, the velocity of the moving interface or medium can be calculated. The Doppler information thus collected can be superimposed on a real-time ultrasonic image, with a color scale assigned to indicate the rate at which blood is flowing in specific parts of the area imaged. This particular technique has made possible ultrasonic studies of the heart and vascular system.

Although the resolution of ultrasound imaging is rather poor, this technique is still clinically quite useful. For instance, it is a modality ideally suited to the examination of pregnant women (to monitor fetal development, in particular) as well as the examination of the abdomen because the sonic energy typically used in clinical application has no known deleterious biological effects. In addition, the real time nature and operator selectable field of view of these studies make this an extremely versatile techuique and can give an immediate understanding of the anatomical features under scrutiny. Finally, the imaging capabilities of this technique are continually progressing. At present, efforts are being made to produce three dimensional real time ultrasonic images, although this particular application is still in its developmental stages. 


\section{Medical Imaging Technologies Survey}

\section{Ultrasound}

SYSTEMS IMAGED:

Abdominal, fetal and vascular system studies

FORM OF IMAGE:

Planar projection (axis is operator selectable) 3-D imaging is also possible - see Figure 3

QUALITY OF IMAGE:

Fair

RESOLUTION:

SPATIAL RESOLUTION:

Axial resolution: $1-2 \mathrm{~mm}$

Lateral resolution: $1-10 \mathrm{~mm}$

TEMPORAL RESOLUTION:

Real time imaging

(15 frames/sec)

ELEMENTAL RESOLUTION:

None

NON/INVASIVE:

Noninvasive (patient must drink large amounts of water to eliminate gas pockets)

RADIATION EXPOSURE: None

IN/OUTPATIENT:

Outpatient

RISK:

MORTALITY:

None

MORBIDITY:

None

MATURITY:

Real-time ultrasound: Mature (10-15 years)

AVAILABILITY:

Common (all hospitals)

COST:

WHOLE FACILITY:

$\$ 80,000 .-\$ 220,000$.

PER USE:

$\$ 240$.

UTILITY:

Common clinical use - especially used for obstetrics

Doppler ultrasound provides blood flow information 


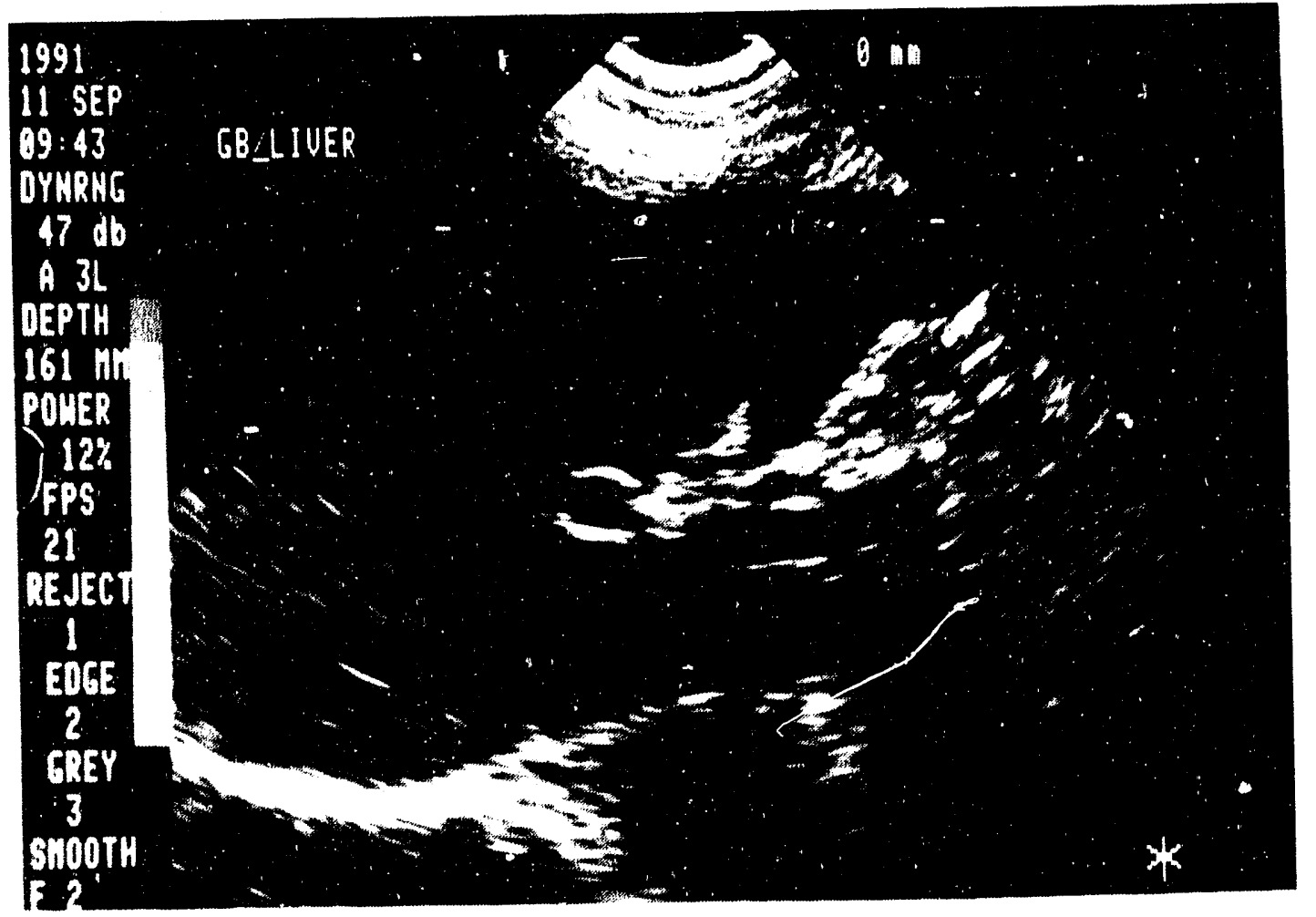

Figure 6: Ultrasound image of gall bladder and liver (source: T. Button, University Hospital of SUNY at Stony Brook). 


\section{Nuclear Medicine: PETT, SPECT, and Radionuclide Ventriculography}

Nuclear medicine has become an increasingly popular diagnostic tool. Unique in its ability to image the functional activity of the organs or structures under scrutiny, it ultimately provides the physician with a greater understanding of the function of the organs imaged rather than detailing any of their anatomical features. At present, nuclear medicine facilities are commonly found in most hospitals, and nuclear medicine itself plays an integral part in the ever-developing field of diagnostic medicine.

Nuclear medicine is based on the premise that certain chemicals or biomolecules that have an affinity for specific organs or structures in the body can be labelled with radioactive atoms. After these radionuclide-tagged substances (or 'radiopharmaceuticals') are injected intravenously or are ingested, they collect in their target area(s), and the decay of the radioactive substance can be recorded by gamma or scintillation cameras. These data can be translated by a digital processing system into an image of the concentration of the radiopharmaceutical in the tissues in question. In consequence, the biochemical behavior of these specific structures can be monitored; unusually high or low accumulations of the radiopharmaceuticals in the tissues imaged indicate areas of pathology, as they indicate variations in the function of these tissues.

Nuclear medicine studies can be either static or dynamic. Static studies are images taken of an area over an extended amount of time, showing the distribution of the radiotracer and/or the overall function of the area. Dynamic studies are a compilation of images taken at periodic intervals, and can show the actual movement of the radioisotope through the vascular system and thus through the organs under observatiu. . Dynamic studies can provide quantitative data (such as the amount of blood the heart pumps per second) and can thus provide functional information.

The principles of nuclear medicine can be applied to emission computed tomography. Emission computed tomography allows depth information to be obtained, since this digital image acquisition process allows overlying and underlying source activities to be eliminated from the final tomographic image. As a result, multiple slices of an organ or structure can be obtained and displayed.

Two major divisions of nuclear medicine, PETT (Positron Emission Transaxial Tomography) and SPECT (Single Photon Emission Computed Tomography), have emerged. They differ in the way the internally administered radioisotopes employed in each procedure decay, and in the way this decay is detected.

Positron emitters produce annihilation coincidence radiation, which is characteristic gamma radiation given off when a positron emitted by the radioactive substance encounters an electron and they annihilate each other. The result is the release of two $511 \mathrm{keV}$ photons which travel in opposite directions simultaneously. These two photons are therefore distinguishable from all other photons being emitted at this time, and 
a line along which this decay took place can be determined from the two points of their detection on the circular bank of scintillation detectors employed in this technique. In consequence, an axial planar image of the distribution of the radionuclide in the tissues or organs in question can be digitally reconstructed. This distribution reveals the relative absorption and, ultimately, the metabolic activity of the tissues being examined. In addition, PETT scanners also perform three-dimensional (3-D) imaging. For such imaging, the patient is moved and a series of tomographs is recorded producing digitally compiled 3-D images.

The positron emitters used in PETT studies are radioactive isotopes of elements commonly found in the body (such as ${ }^{18} \mathrm{~F}$, a hydrogen substitute, ${ }^{11} \mathrm{C},{ }^{15} \mathrm{O}$, and ${ }^{13} \mathrm{~N}$ ). There is no chance that these isotopes will trigger an allergic reaction in the patient. Since these isotopes have exactly the same chemical properties as their non-radioactive counterparts, they can easily replace these elements in various biomolecules usually found in the body. The chemical behavior or function of these biomolecules will not be altered by this substitution, but their biochemical activity can now be easily observed and monitored by the PETT technique.

Over 500 compounds have been labeled with the isotopes ${ }^{18} \mathrm{~F},{ }^{15} \mathrm{O},{ }^{13} \mathrm{~N}$, and ${ }^{11} \mathrm{C}$. They range from the most basic molecules such as ${ }^{18} \mathrm{~F}$-labeled D-Glucose (called 2Deoxy-2[ $\left[{ }^{18} \mathrm{~F}\right]$ Fluoro-D-Glucose, or simply FDG), ${ }^{15} \mathrm{O}$-labeled water, and ${ }^{13} \mathrm{~N}$-labeled ammonia to more complex molecules such as amino acids, fatty acids, catalytic substrates, analogs, and drugs. Since the biochemical function of each of these substances remains unchanged, researchers have a means to observe the metabolic activity of such organs as the brain and heart and such structures as tumors, and to map the mechanisms of neuroreceptors. In effect, PETT grants researchers the unique opportunity to monitor, in vivo, the progress of disease and theraputic response.

FDG is a particlarily important compound in both heart and brain imaging. In the normal heart (and especially in the fasting state) fatty acid metabolism is the predominant source of myocardial energy production. However, when the heart has been damaged (if, for instance, cardiac ischemia has occured) the heart uses glucose as one of its energy sources. Consequently, FDG can be used to assess the damage suffered by the cardiac wall since it allows health professionals to observe the metabolic function of these tissues. From such information, an appropriate course of treatment can be devised. FDG is also a substance that can be used to monitor the brain's metabolic activity because glucose is the brain's main energy source. In consequence, researchers have a means to study and differentiate between various neurological disorders by identifying specific patterns of glucose metabolism imaged with the help of this technique. In particular, schizophrenia, Alzheimer's disease, cerebral malignancies (such as glioblastoma), drug mechanisms, and the effects of substance abuse can be researched with PETT imaging.

The positron-emitting isotopes used in PETT imaging require near-by cyclotron production since they have extremely short half-lives - usually on the order of a few minutes. The installation and upkeep of a cyclotron facility is expensive and demands 
the attention of qualified personnel. In consequence, positron tomography is not yet practical for routine diagnostic imaging, but is, at present, better suited for clinical research.

The single photon emitters used in SPECT, on the other hand, decay by emitting gamma radiation. These gamma ray emissions can be picked up by a scintillation gamma camera which may have a single or multiple head. These gamma emissions are also digitally compiled and organized to produce a computer generated image of the distribution of the radioisotope in the tissues. It must be noted, however that the gamma ray scintillation cameras employed in SPECT imaging only detect and record gamma rays that strike the camera at a specific angle so that an image representative of the organ containing the radiopharmaceutical can be formed. In consequence, this imaging technique depends on the collimation of the emitted gamma rays.

A collimator is a device which assures the alignment of the incoming gamma rays, since it eliminates all rays not coming within a range of angles suitable for collection by the gamma camera. Collimators are not necessary in PETT imaging, since all the coincident gamma rays given off within the slice of the body being imaged can be recorded by the ring of detectors around the patient. For this reason, PETT imaging systems are more efficient, sensitive, and have better resolving capabilities than SPECT imaging systems, whose collimators absorb or scatter $99 \%$ of the emitted gamma rays. Therefore, in comparison, a greater portion of the radioisotope dose given to the patient is used for imaging in PETT studies than in SPECT studies. However, it is important to note that patient movement during PETT imaging can cause a significant loss of resolution, and so an effort must be made to avoid such movement. In consequence, PETT requires immobilization procedures that are not as necessary in SPECT imaging.

The SPECT imaging technique is an extremely adaptible and versatile technology. The gamma cameras used in this technique can be kept stationary and allow an entire organ to be viewed, or the cameras can be rotated (usually $180^{\circ}$ or $360^{\circ}$ ) around the patient in order to obtain an axial tomographic slice of an area. SPECT studies, which, like PETT imaging, can be static or dynamic, can also be gated. This means that such studies can be calibrated to image the heart, for instance, at the same point in the cardiac cycle over several heartbeats. Finally, the gamma camera can be moved along the body's longitudinal axis so that a planar whole body image can be produced. The movable head of the gamma camera used in SPECT imaging studies is thus easily positioned wherever needed during each study, and so SPECT studies do not involve as precise patient-positioning procedures as required by PETT. In consequence, SPECT is an easily manipulated, handy diagnostic tool of routine clinical use. In effect, the temporal resolution and radiation exposure involved in this technique vary as required by each particular study and by the radiopharmaceutical employed in each procedure.

In addition, SPECT imaging has the advantage of employing single photon emitting isotopes (such as ${ }^{99 m} \mathrm{Tc},{ }^{201} \mathrm{Tl}$, and ${ }^{123} \mathrm{I}$, for example), which are practical for 
more routine use since they are commercially available from pharmaceutical companies and have half-lives between six hours and several days. The half-lives of these single photon emitters are thus long enough to permit good imaging results, but not so long as to unnecessarily irradiate the patient. Although allergic reaction to these radiopharmaceuticals is possible, the risk is quite low, and the reaction itself (usually expressed as a rash) is not very severe.

At present, SPECT imaging is more clinically useful than PETT imaging, thanks to its versatile imaging capabilities and more readily accessible radioisotopes. Nevertheless, PETT is proving to be an invaluable tool in the field of medical research and will someday prove useful for clinical use.

Radionuclide ventriculography (RVG) is an example of a dynamic nuclear medicine technique utilizing a single photon emitter. This particular technique images the functional activity of the walls of the heart as the red blood cells are being pumped in and out of the heart's ventricles. A cine mode display of the study shows a fair visual result as to the extent of damage wrought by cardiac arrest. However, the calculation of the ejection fraction (which is the amount of blood ejected from the ventricles for every heart beat) from the digitized images gives an accurate measure of the health of the ventricular walls.

When performing RVG, the patient is given an intravenous injection of stannous pyrophosphate which attaches to the red blood cells. Fifteen minutes later, the patient is injected with a 25 to $30 \mathrm{mCi}$ dose of technetium $-99 \mathrm{~m}$ pertechnetate which has a half-life of 6 hours and readily binds to the stannous pyrophosphate, thus transporting the ${ }^{99 \mathrm{~m}} \mathrm{Tc}$ to the heart. The decay of the technetium produces gamma rays. These rays are picked up and recorded by a gamma camera with the patient positioned in the modified left anterior oblique projection (for best separation of the left and right ventricles). Image acquisition is performed in a gated mode with a camera linked to a computer.

The resulting computer images can be viewed in a cine mode display where 32 digitized images are sequentially projected onto a viewing screen. This mode of display allows health professionals to watch the heart expand and contract and monitor the movement of the ${ }^{99 \mathrm{~m}} \mathrm{Tc}$ tagged red blood cells within the cardiac walls during the course of a heart beat.

Such RVG imaging is performed within 24 hours after the heart attack occurs. A second study is performed immediately before discharge which could be 8-10 days after the heart attack. A third study is also performed 6 weeks after the heart attack as an outpatient procedure. Consequently, the magnitude of the damage experienced by the heart in the wake of a heart attack and the degree to which the cardiac muscle has healed in the period following the heart attack can be easily ascertained from a comparison of these images. 
Because this technique reveals the viability of the tissues of the heart, it is also an ideal method to moniter the effects of drugs being developed to aid the recovery of heart attack victims. Another advantage is that this procedure is not at all taxing to patients recovering from heart attack and is extremely low risk. For these reasons, RVG is a technique well suited to the study of drug effectiveness in cardiac research. 


\section{Medical Imaging Technologies Survey}

Nuclear Medicine: Positron Emission Transaxial Tomography (PETT)

SYSTEMS IMAGED:

FORM OF IMAGE:

QUALITY OF IMAGE:

RESOLUTION:

SPATIAL RESOLUTION:

TEMPORAL RESOLUTION:

ELEMENTAL RESOLUTION:

NON/INVASIVE:

RADIATION EXPOSURE:

IN/OUTPATIENT:

RISK:

MORTALITY:

MORBIDITY:

MATURITY:

AVAILABILITY:

COST:

WHOLE FACILITY:

PER USE:

UTILITY:
Brain, tumors, heart (metabolic mapping and receptor imaging)

Computer generated image of tomographic axial plane - see Figures 7, 8

3-D imaging also possible

Image in terms of anatomy: Fair to Good

Image in terms of substrate metabolism, regional blood flow and receptors: Excellent

\section{$6.75 \mathrm{~mm}$}

Static studies: $\sim 20 \mathrm{~min}$

Dynamic studies: $40 \mathrm{~min}$ to 3 hours (depending on study)

None

Noninvasive (radiolabelled biomolecules are introduced intravenously)

Whole body: $100-1000$ mrads

Critical organ: 300 mrads -1.8 rads

Outpatient

None

Low (no allergic reactions; all radioisotopes are naturally occuring elements of the body)

Developing (about $10-15$ years)

Rare (only 50 such facilities in U.S.)

$\$ 5$ million.

$\$ 1500,-\$ 2000$.

$80 \%$ of U.S. facilities are engaged in research, and $20 \%$ are clinically operative Eventually, this technique will become a more common diagnostic tool 


\section{Medical Imaging Technologies Survey}

Nuclear Medicine: Single Photon Emission Computed Tomography (SPECT)

SYSTEMS IMAGED:

FORM OF IMAGE:

QUALITY OF IMAGE:

RESOLUTION:

SPATIAL RESOLUTION:

TEMPORAL RESOLUTION:

ELEMENTAL RESOLUTION:

NON/INVASIVE:

RADIATION DOSE:

IN/OUTPATIENT:

RISK:

MORTALITY:

MORBIDITY:

MATURITY:

AVAILABILITY:

COST:

WHOLE FACILITY:

PER USE:

UTILITY:
Whole body

Tomographic axial images and planar projections - see Figure 9

Image in terms of anatomy: Fair Image in terms of function: Excellent

$1 \mathrm{~cm}$

Varies according to particular application and isotope

None

Noninvasive (radioactive isotopes are either injected or ingested)

Usually between $2-30 \mathrm{mCi}$

Outpatient (hospital stay required for lodine-131 because of 8 day half-life)

None

$0.004 \%$ chance of allergic reaction (expressed as rash - nothing fatal)

Mature (30 - 40 years)

Very common (most hospitals in U.S. have SPECT' facilities)

$\$ 200,000$. $-\$ 1$ million.

$\$ 100 .-\$ 1000$. depending on particular procedure

Clinical diagnostic use 


\section{Medical Imaging Technologies Survey}

\section{Nuclear Medicine: Radionuclide Ventriculography (RNV)}

SYSTEMS IMAGED:

FORM OF IMAGE:

QUALITY OF IMAGE:

RESOLUTION:

SPATIAL RESOLUTIOiv:

TEMPORAL RESOLUTION:

ELEMENTAL RESOLIITION:

NON/INVASIVE:

RADIATION EXPOSURE:

IN/OUTPATIENT:

RISK:

MORTALITY:

MORBIDITY:

MATURITY:

AVAILABILITY:

COST:

WHOLE FACILITY:

PER USE:

UTILITY:
Heart (wall motion study)

Computer generated planar projection (left anterior oblique view)

Image in terms of anatomy: Poor

Image in terms of organ function: Excellent

$6 \mathrm{~mm}(64 \times 64$ pixels $)$

3 - 10 minutes (depending on attenuation of patient; imaging is performed until 5 million counts are recorded)

None

Noninvasive (but requires venous injections)

$25-30 \mathrm{mCi}$

Inpatient (usually 8 - 10 days' stay)

Outpatient (6 weeks from day 1 of hospital stay)

None

Low (although allergic reaction to radiopharmaceutical is possible)

Mature (approximately 20 years)

Common (most hospitals have nuclear medicine facilities)

$\$ 300,000$. - $\$ 400,000$.

$\$ 460 .-\$ 800$.

Clinical use possible Mostly research at present (ie. contributes to the development of drugs for heart attack patients) 
-

$-54-$ 


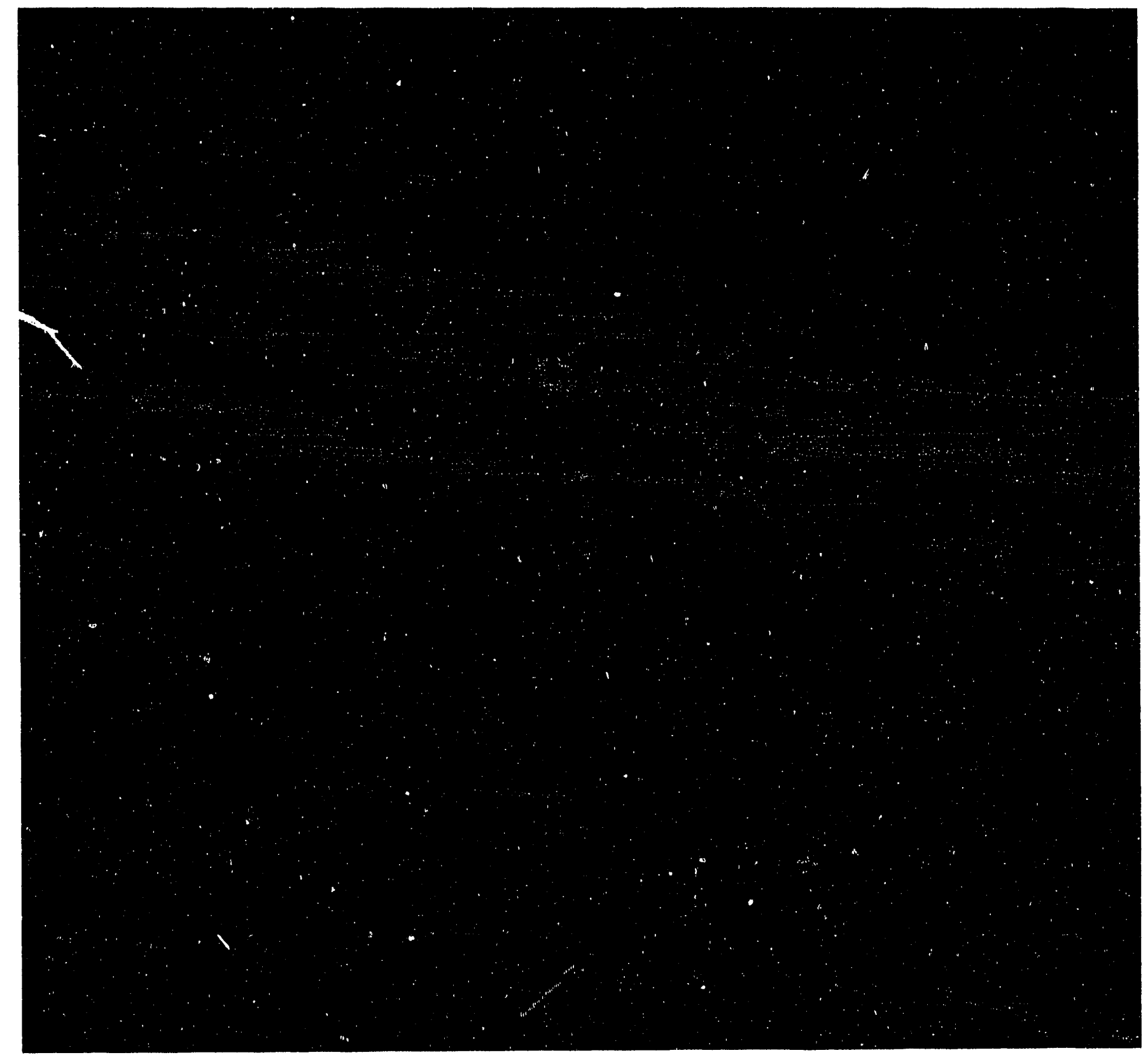

Figure 7: PETT axial tomographic images of normal brain activity using ${ }^{18} \mathrm{~F}$ labeled glucose, ie. FDG (source: G-J. Wang and N. Pappas, PETT VI at $\mathrm{BNL}$ ). 


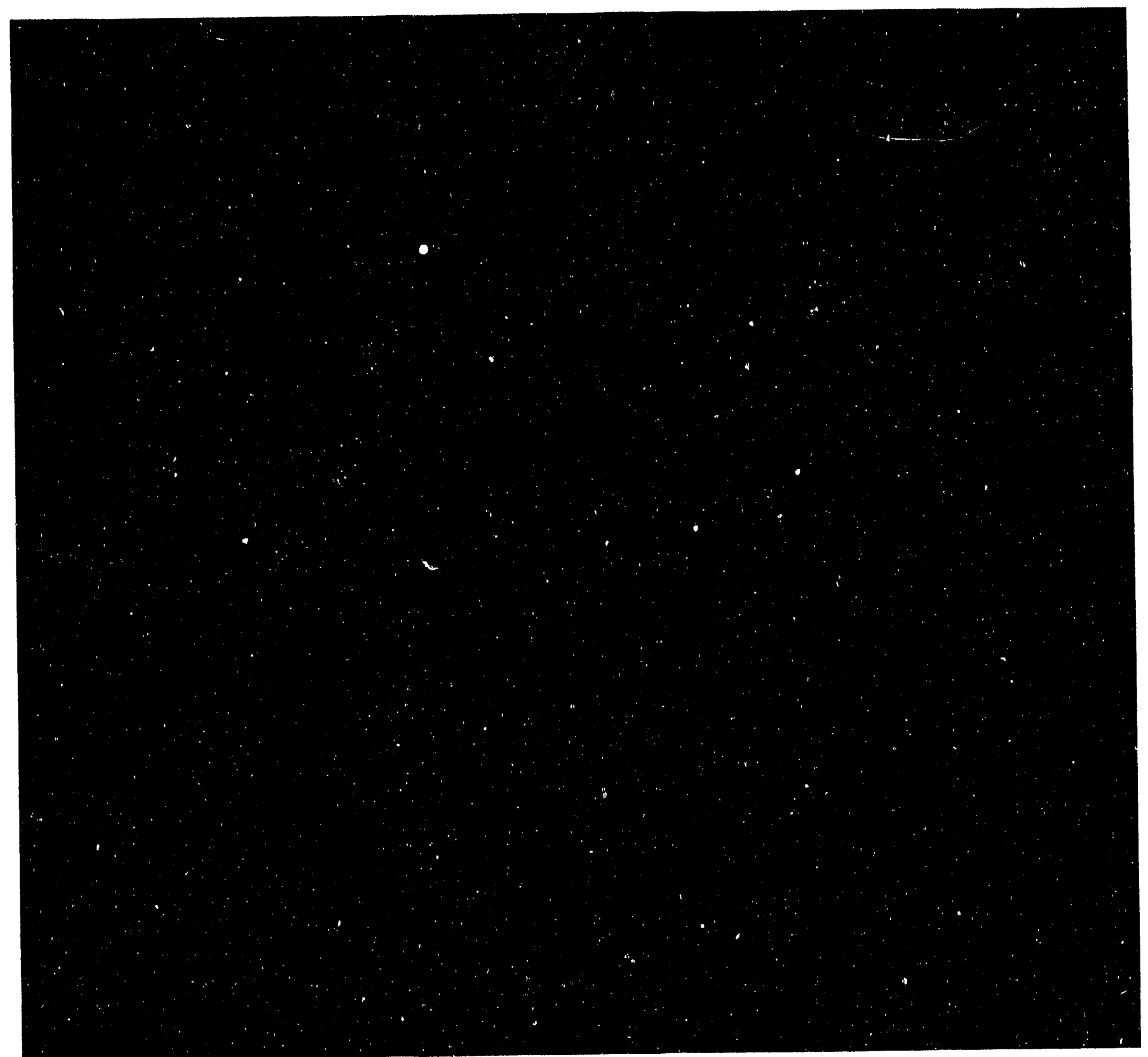

Figure 8: PETT axial tomographic images of schizophrenic brain activity using ${ }^{18}$ F-labeled glucose, ie. FDG (source: G-J. Wang and N. Pappas, PETT VI at BNL). 


\section{$\longrightarrow$}



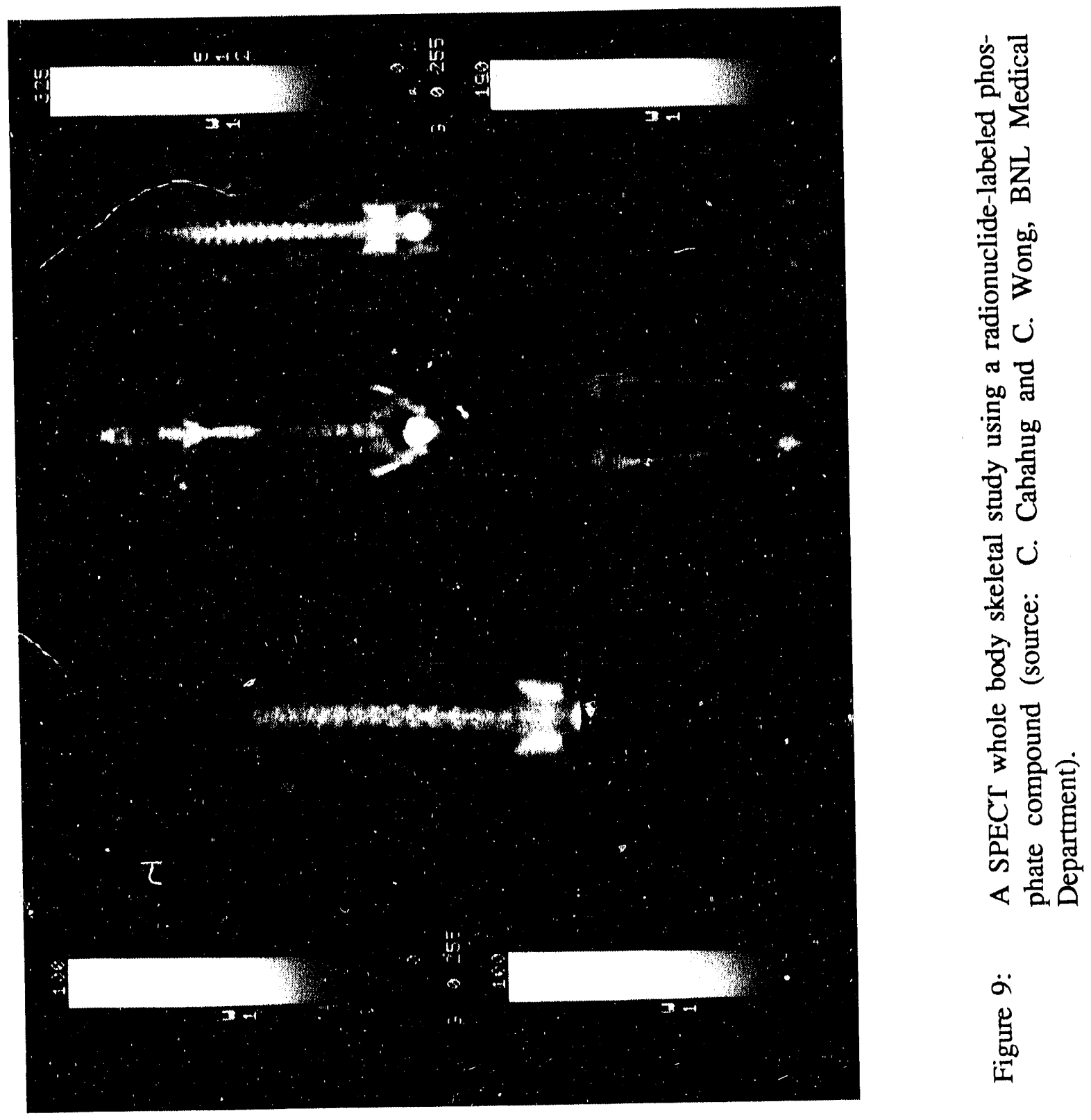


\section{Magnetic Resonance Imaging}

Magnetic Resonance Imaging (MRI) is one of the most versatile and rapidly developing imaging technologies in use at present. The MRI technique is an extension of Nuclear Magnetic Resonance (NMR) spectroscopy, in that an NMR spectrum of a particular isotope (or more precisely, a group of identical nuclei) obtained in the presence of a magnetic field gradient is actually just a projection of an image of the concentration of these nuclei.

The MRI technique uses the basic physical properties of the atomic nucleus to obtain a tomographic image of the human body. The concept of magnetic resonance is founded on the premise that nuclei with uneven numbers of protons or neutrons display magnetic properties and have a weak magnetic moment; that is, the nuclei behave like tiny dipole magnets. Under normal circumstances, the nuclear magnetic moments are randomly oriented. But when exposed to a strong external magnetic field of the order of 1.5 Tesla or 30,000 times the magnetic field of the Earth, a magnitude used for MRI, the nuclei will align themselves parallel to this external field, either pointing with or against it. The number of nuclei pointing in each direction is nearly the same, except that an additional one in a million nuclei will point with the magnetic field, a state of slightly lower energy. It is these excess nuclei that give the net NMR signal used in imaging.

While nuclei are aligned with an external magnetic field, the magnetic moment of each individual nucleus precesses about the magnetic field direction at a specific rate called the Larmor frequency. The Larmor frequency is proportional to the local magnetic field; as the magnetic field increases, the frequency at which the nuclei precess increases as well. In consequence, a magnetic field gradient across a sample of nuclei means that differeni nuclei in the sample will precess at different frequencies. In effect, the resulting NMR spectrum produced by this sample can reveal spatial information about the state of individual nuclei.

The NMR spectrum of a particular sample can be acquired by subjecting the nuclei in the sample to a radio frequency (RF) magnetic pulse, which is generated by applying an alternating current to an RF coil. The coil serves as both a transmitter and a receiver of RF. If the frequency of this RF pulse is comparable to the Larmor frequency, the nuclei will be tipped relative to the DC field. The nuclear magnetization is usually rotated through either $90^{\circ}$ or $180^{\circ}$, depending upon the length of time the nuclei are exposed to the RF pulse. When the RF signal is removed, the nuclei will realign themselves along the original magnetic field direction and will precess about it. This return motion induces the NMR signal from which an NMR spectrum can be obtained and ultimately from which an image representative of the location of the particular nuclei in the sample under study can be created.

The nuclear realignment is characterized by two time constants (relaxation times) called $T_{1}$ and $T_{2}$. The length of these relaxation times is dependant on the nature of the tissue in which the nuclei are situated. In general, the lower the concentration of 
macromolecules (such as proteins) in the vicinity of the 'realigning' nuclei, the longer the relaxation time. $\mathrm{T}_{1}$ is the "spin-lattice" relaxation time, and is determined by how quickly nuclel can transfer energy to their lattice or surroundings in their return to a lower energy state. $T_{2}$ is the "spin-spin" relaxation time, and is determined by the speed at which the nuclei can transfer energy among themselves in order to achieve a random distribution of the nuclei precessing about the direction of the original field.

The MRI installation consists of a superconducting solenoid large enough to immerse the entire patient in a uniform magnetic field. Other coils installed inside this solenoid provide magnetic field gradients in the $x, y$, and $z$ directions. Finally, RF coils are installed directly around the patient in such a way that the patient can be exposed to RF pulses and so multiplanar images can be produced.

The actual images generated by MRI are produced by varying the magnetic field gradient sequentially in the three dimensions allowing a slice to be imaged according to the NMR spectroscopy principles outlined above. A computer can digitally compile the spectra produced with each gradient direction to produce an image representative of the number of specific nuclei in the tomographic slice or their magnetic properties, which are characteristic of the tissue in which they reside.

Most MRI studies are calibrated to image the concentration or properties of protons (the ${ }^{1} \mathrm{H}$ isotope of hydrogen) in the body. The proton has one of the largest magnetic moments of all nuclei that display magnetic properties, and is also very abundant in the body. In consequence, proton-calibrated MRI studies essentially show the distribution of water in the tissues. Differences in tissue density or properties are thus very clearly contrasted in MRI studies.

It is also possible to calibrate the system (by tuning the RF to the appropriate frequency) so that the concentrations of other stable nuclei with fairly strong magnetic moments (such as ${ }^{23} \mathrm{Na},{ }^{31} \mathrm{P}$ or ${ }^{13} \mathrm{C}$ ) can be imaged. Phosphorus imaging, for example, can reveal the absorption capability and thus the function and metabolic activity of heart tissue.

Patient movement is of great concern during MRI studies. The resolution of the resulting image is very much reduced if the patient moves during the long scan time (often between $1 / 2$ hour and 1 hour) of these studies. However, 'Iltrafast' MRI is currently being developed. This MR technique can actually obtain a single tomographic slice in less than a second.

It is also possible to gate the fast switching magnetic field gradients in MRI in a procedure called gated MR acquisition. With this technique, it is possible to image the heart at any specific point in the cardiac cycle by using an ECG (electrocardiogram) signal to trigger the RF pulses. 
MRI is especially useful for the differentiation of the vascular system from surrounding tissues. In fact, a new technique called Magnetic Resonance Anglography (MRA) is being developed. It is possible to differentiate hydrogen atoms that are moving from those that aren't since they move through the field gradients, and their resonant frequency changes as a function of time. In consequence, the protons moving in the blood stream can be differentiated from those in the surrounding tissues. The 'stationary' protons can be subtracted from the MR image, and only an image of the blood will remain. MRA also allows blood flow to be measured, but as yet the technology only produces good results for the larger blood vessels.

Contrast agents can be used in MRI to even further improve the tissue contrast resolution. These agents are not dyes, but are nondiamagnetic substances. The contrast agents function by disturbing the local magnetic field values in the body. However, MRA can be performed without the use of any contrast agents by simply taking advantage of the blood motion.

Finally, the two relaxation time constants $\left(T_{1}\right.$ and $\left.T_{2}\right)$ can play a part in improving image resolution. $M R$ images can be $T_{1}-$ or $T_{2}$-weighted by changing the $R F$ pulse sequencing parameters. In this way, the contrast of the MR images can be manipulated since contrast is controlled by the time response of the NMR signal from the body. This contrast manipulation capability may aid the detection of cancerous tissue, since malignant tissues have a longer $T_{1}$ relaxation time than normal tissues. Ultmately, the MRI technique may help pinpoint diseased tissue at an earlier stage than is currently possible.

In summation, MRI is a technique which has much to offer the diagnostic imaging industry. Its many advantages include excellent spatial resolution, no harmful biological effects (because the technique involves no ionizing radiation), good tissue contrast, information on certain metabolic processes in the body, and operator selectable plane image formation. Three dimensional images can also be digitally constructed from multiplanar studies. In effect, MRI is one of the most rapidly developing and versatile imaging modalities in use at present. 


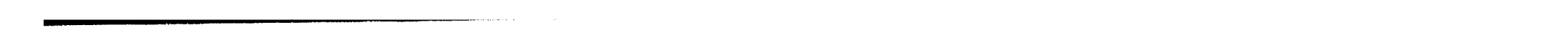




\section{Medical Imaging Technologies Survey}

\section{Magnetic Resonance Imaging (MRI)}

SYSTEMS IMAGED:

FORM OF IMAGE:

QUALITY OF IMAGE:

RESOLUTION:

SPATIAL RESOLUTION:

TEMPORAL RESOLUTION:

ELEMENTAL RESOLUTION:

NON/INVASIVE:

RADIATION EXPOSURE:

IN/OUTPATIENT:

RISK:

MORTALITY:

MORBIDITY:

MATURITY:

AVAILABILITY:

COST:

WHOLE FACILITY:

PER USE:

UTILITY:
Whole tody (anatomical structures)

Planar projection (any axis possible)

See Figure 10 (3-D images also possible)

Excellent

$1 \mathrm{~mm}$

Usually $0.5-1 \mathrm{hr}$

(Ultrafast MRI allows subsecond imaging)

Complete detection for specified elements (eg. protons, phosphorus-31, or carbon-13, depending upon the particular study)

Noninvasive (contrast agents are sometimes injected to improve image contrast)

None

Outpatient

None

None $(10-15 \%$ of patients experience claustrophobia)

NMR Spectroscopy: Mature ( -45 years) MRI: Developing ( -10 years)

Relatively rare; between 1000 and 1500 such facilities exist in the U.S.

$\$ 2$ million.

$\$ 1000$.

Primarily routine clinical use

Also aids in physiological and pathological research studies 


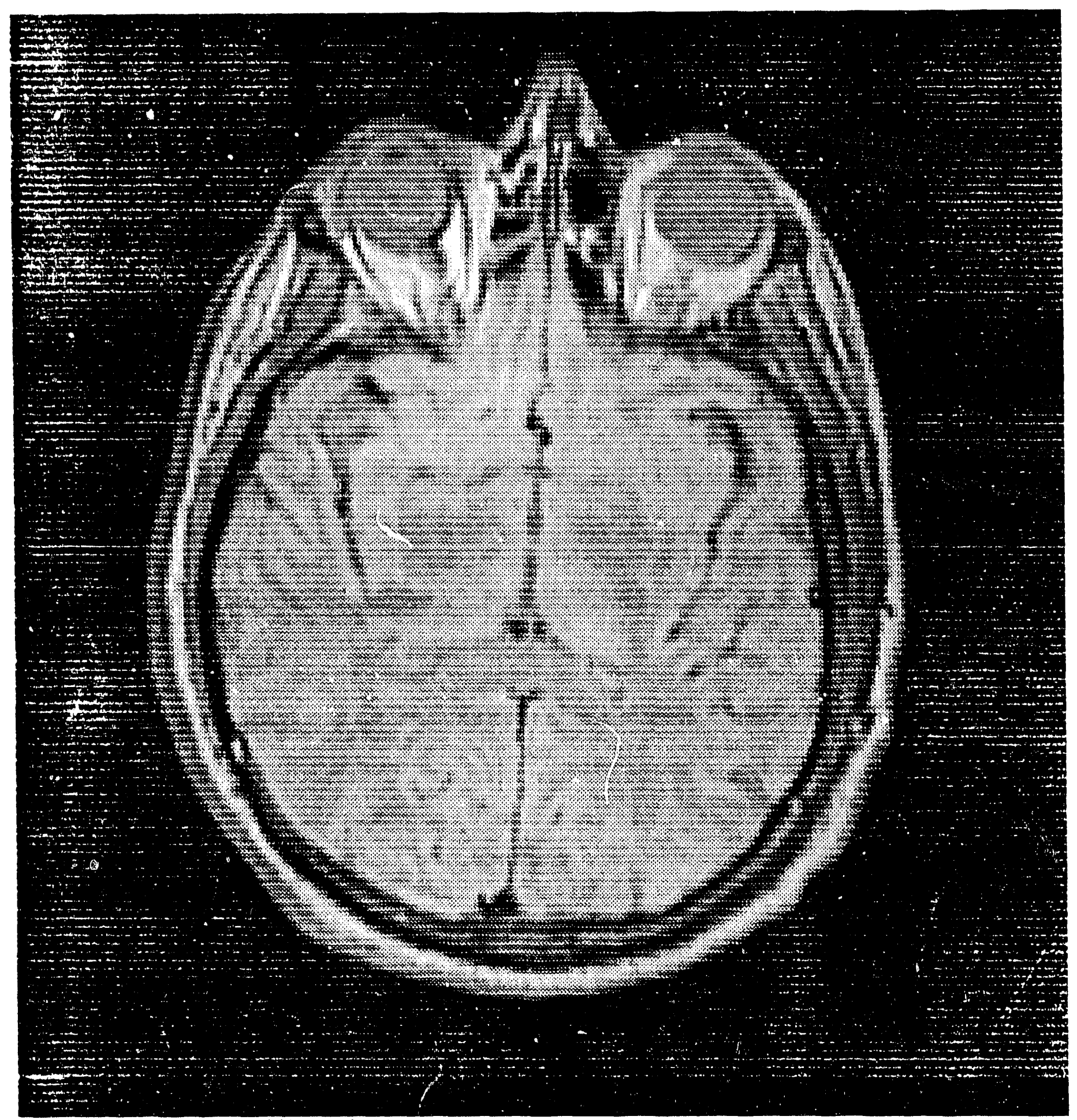

brain slice superior offset from axial image of $17.3 \mathrm{~mm}$

Figure 10: A very slightly $\mathrm{T}$, -weighted magnetic resonance axial tomographic image of the upper brain. Those regions containing proton spins with shorter $T$, values are darker than those regions containing proton spins with longer $T$, values (source: C. Springer, Unversity Hospitai oi SUNY at Stony Brook). 


\section{Multi-Modality Image Manipulation and Storage System}

Of all the different imaging modalities in use at present, each has, by nature, its own strong points and weak points. No one imaging technique (as yet) can provide all the information required to diagnose any ailment. For instance, nuclear medicine techniques (such as PETT and SPECT) can reveal much about the function and activity of the structures imaged, while MRI and CT imaging techniques provide superior anatomical detail. Each of these techniques has its own inherent advantages and limitations, but no technique can provide all the answers.

The creation of a multi-modality information manipulation and storage system could be, of great benefit to the field of diagnostic imaging. The ability to call up the images of different diagnostic imaging techniques onto a single screen could permit the coordination of the collected data to a degree not previously possible. Ultimately, this system would be of great advantage to the field of medical diagnosis. This concept would grant medical personnel the unique opportunity to correlate observed changes in function (as depicted by nuclear imaging techniques, for instance) with corresponding changes in structure (as shown by such techniques as CT or MRI). The potential clinical applications and research capabilities of such a system are extensive.

At present, this integrated concept is still in its infancy. The images presented here (see Figure 11) were compiled at the Medical Department of Brookhaven National Laboratory. These images simply depict what sort of information could be manipulated by such an image storage system. They are not presently useable due to the fact that none of the individual images depict the same person. However, this presentation gives an idea of the capabilities of such a system. The digitalization and display of correlated images from different imaging techniques would be a powerful diagnostic tool of great benefit to the medical community. 
$-70$ 

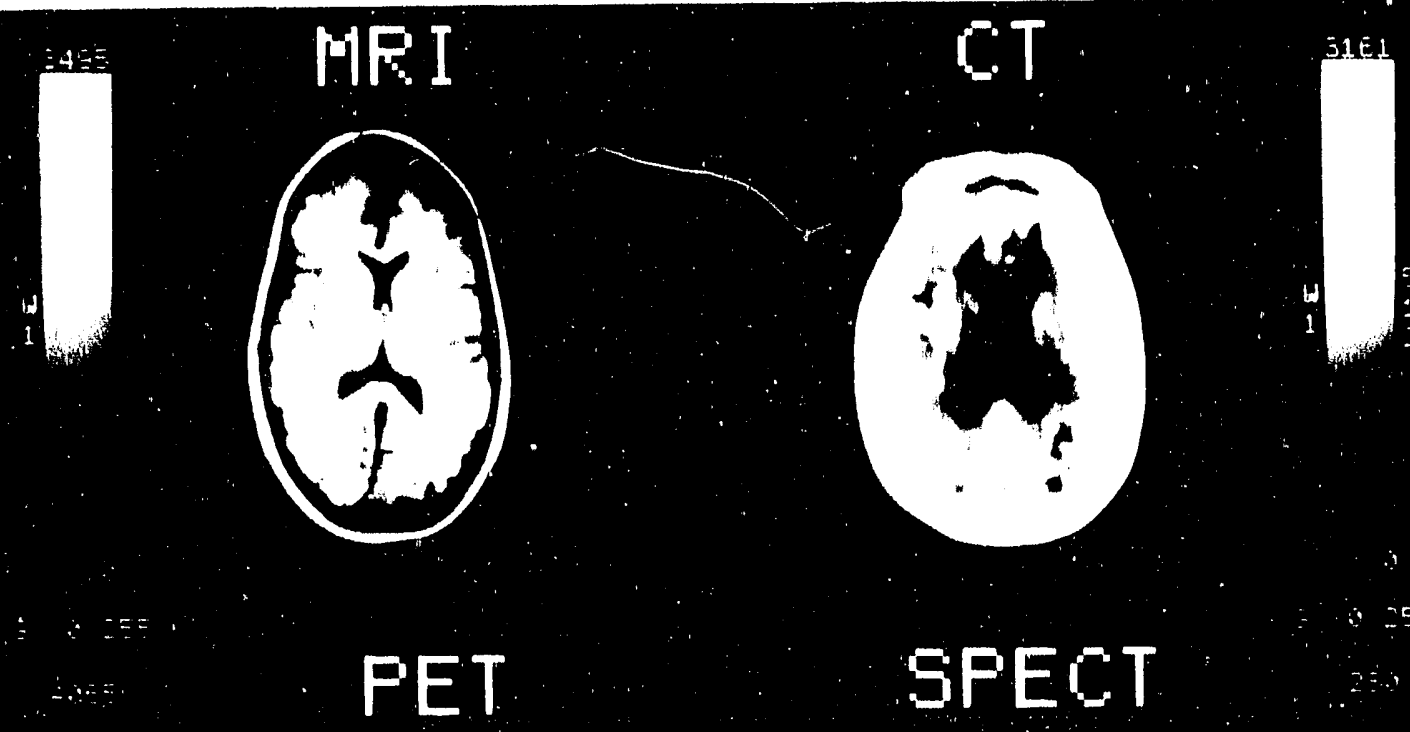

SPECT

(ntis
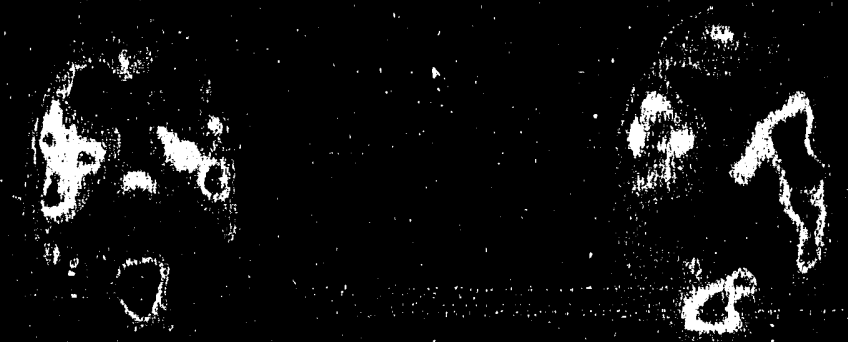

Figure 11: The multi-modality image storage system (source: BNL Medical Department).

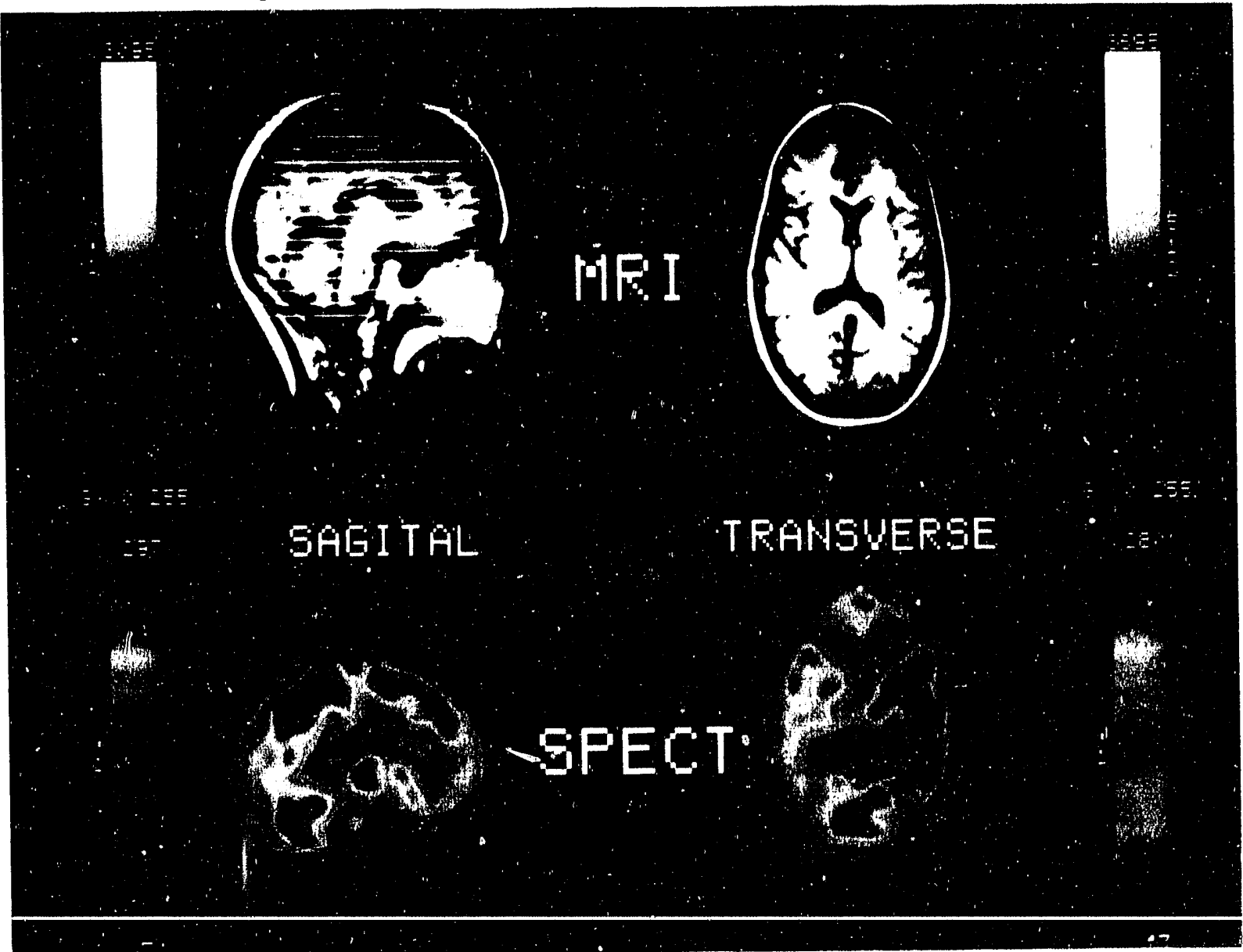




\section{Acknowledgements}

This report could not have been written without the cooperation and guidance of all those listed below. I can't thank them enough for their time and effort, for the information and the images with which they were able to provide me, and for their extensive editing skills. Their unfailing support and enthusiasm have further encouraged me to pursue a career in the field of medicine.

I. The Whole Body Counter

Dr. Avraham Dilmanian (BNL Medical Department)

II. X-ray Radiology

William Lehman (BNL Medical Department)

Dr. Hal Atkins (University Hospital of SUNY at Stony Brook)

III. Conventional Angiography

Dr. John Morrison (North Shore University Hospital)

IV. Transvenous Angiography

Dr. William Thomlinson, Nicholas Gmür (BNL National Synchrotron Light Source)

V. Computed Tomography

Dr. Terry Button (University Hospital of SUNY at Stony Brook)

- MECT

Dr. William Thomlinson (BNL National Synchrotron Light Source)

VI. Ultrasound

Dr. Terry Button (University Hospital of SUNY at Stony Brook)

VII. Nuclear Medicine

Dr. Hal Atkins (University Hospital of SUNY at Stony Brook)

- PETT

Dr. Gene-Jack Wang, Naomi Pappas (PETT VI at BNL)

- SPECT

Dr. Cora Cabahug, Dr. Christopher Wong (BNL Medical Department)

- Radionuclide Ventriculography

Benilda Valdellon (North Shore University Hospital)

VIII. MRI

Dr. Charles Springer (University Hospital of SUNY at Stony Brook)

IX. Multi-modality Imaging System

Fabrice Hodé (BNL Medical Department) 
$-74-$ 


\section{Suggested Readings}

\section{X-Ray Radiology:}

1. Brody, William R. 1984. Digital Radiography, Raven Press, New York, NY. 83-85.

2. Curry, Thomas S. III, James E. Dowdey, Robert C. Murray. 1990. Christensen's Physics of Diagnostic Radiology. Fourth Edition. Lea \& Febiger, Philadelphia, PA. 10-36, 61-69, 99-101, 165-170.

3. Sider, Lee (Editor). 1986. Introduction to Diagnostic Imaging. Churchill Livingstone Inc., New York, NY. 2-10.

\section{Conventional Angiography}

1. Belford, Marsha. "Human Heart Scanned Successfully with NSLS X-Rays." Brookhaven Bulletin, Volume 44-No. 41, October 19, 1990. 1-2.

2. Brody, William R. 1984. Digital Radiography. Raven Press, New York, NY. 83104.

3. Sochurek, Howard. "Medicine's New Vision." National Geographic, Vol. 171-No. 1, January 1987. 20-24, 30-33.

\section{Transvenous Angiography}

1. Belford, Marsha. "Human Heart Scanned Successfully with NSLS X-Rays." Brookhaven Bulletin, Volume 44-No. 41, October 19, 1990. 1-2.

2. Rowe, Ednor M. and John H. Weaver. "The Uses of Synchrotron Radiation." Scientific American, June 1977. 32-41.

3. Thomlinson, W., N. Gmur, H.D. Zeman, J.N. Otis, R. Hofstadter, A.C. Thompson, G.S. Brown, E. Rubenstein, J.C. Giacomini, H.J. Gordon and R.S. Kernoff. 1988. The Synchrotron Radiation Angiography Program at the National Synchrotron Light Source. In: Synchrotron Radiation Applications to Digital Subtraction Angiography (SYRDA), Volume 10 of the Italian Physical Society Conference Proceedings, Frascati, Italy, May 6-8, 1987 (ed. by E Burattini and A. Rindi): 173-180.

4. Thomlinson, W., N. Gmur, D. Chapman, R. Garrett, N. Lazarz, H. Moulin, A.C. Thompson, H.D. Zeman, G.S. Brown, J. Morrison, P. Reiser, V. Padmanabhan, L. Ong, S. Green, J. Giacomini, H. Gordon, E. Rubenstein. 1991. First Operation of the Medical Research Facility at the NSLS for Coronary Angiography. Proceedings of the 
4th International Synchrotron Radiation Instrumentation Conference, Manchester, UK, July 15-19, 1991. Rev. Sci. Instr. (in press). BNL Report 46109.

\section{Computed Tomography}

1. Brody, William R. 1984. Digital Radiography, Raven Press, New York, NY. 47.

2. Dilmanian, F.A. 1991. "Computed Tomography with Monochromatic X-rays from the National Synchrotron Light Source." Nuclear Instruments and Methods in Physics Research B56/57,1991. 1208-1213.

3. Curry, Thomas S. III, James E. Dowdey, and Robert C. Murray, 1990. Christensen's Physics of Diagnostic Radiology. Fourth Edition. Lea \& Febiger, Philadelphia, PA. 289-322.

4. Hasegawa, Bruce H. 1990. The Physics of Medical X-ray Imaging (or The Photon and Me: How I Saw the Light.) First Edition. Medical Physics Publishing Company, Madison, WI. 12-14.

5. Kuni, Christopher C. 1988. Introduction to Computers and Digital Processing in Medical Imaging. Year Book Medical Publishers, Inc., Chicago, IL. 62-74.

6. Sandler, Martin P., James A. Patton, Max I. Shaff, Thomas A. Powers and C. Leon Partain. 1989. Correlative Imaging. Williams \& Wilkins, Baltimore, MD. 56-61.

7. Sider, Lee. (Editor). 1986. Introduction to Diagnostic Imaging. Churchill Livingstone Inc., New York, NY. 21-30.

8. Sochurek, Howard. "Medicine's New Vision." Nátional Geographic, Vol.171, No.1, January 1987. 6-9, 12.

9. Swenberg, Charles E. and James J. Conklin (Editors). 1988. Imaging Techniques in Biology and Medicine. Academic Press Inc., New York, NY. 258-262, 266-299.

10. Tainter, Suzanne. "The Beam's-Eye View." Research News (Univ. of MI Div. of Res. Dev. and Admin.), Vol. 39, No.9-10, September-October 1988. 7-9.

11. The U.S. Diagnostic Imaging Industry (Industry Study Developed for Hambrecht \& Quist, Investment Bankers.) September 1982. 25-30.

\section{Ultrasound}

1. Curry, Thomas S. III, James E. Dowdey, Robert C. Murray. 1990. Christensen's Physics of Diagnostic Radiology. Fourth Edition. Lea \& Febiger, Philadelphia, PA. 
323 371.

2. Kuni, Christopher C. 1988. Introduction to Computers and Digital Processing in Medical Imaging. Year Book Medical Publishers, Inc., Chicago, IL. 112-122.

3. Sancller, Martin P., James A. Patton, Max I. Shaff, Thomas A. Powers and C. Leon Partain. 1989. Correlative imaging, Williams \& Wilkins, Baltimore, MD. 51-56.

4. Sider, Lee (Editor), 1986. Introduction to Diagnostic Imaging. Churchill Livingstone Inc., New York, NY. 10-20.

5. Sochurek, Howard. "Medicine's New Vision." National Geographic, Vol. 171, No. 1, January 1987, 24-30.

6. Swenberg, Charles E. and James J. Conklin (Editors), 1988, Imaging Techniques in Biology and Medicine. Academic Press, New York, NY. 111-165.

7. Tainter, Suzanne. "Interior Journeys." Research News (Univ. of MI Div. of Res. Dev. and Admin.), Vol. 39, No. 9-10, Sept.- Oct. 1988. 11-13.

8. The U.S. Diagnostic Imaging Industry (Industry Study do 'eloped for Hambrecht \& Quist) September 1982. 41-50.

\section{Nuclear Medicine}

1. Daghighian, Farhad, Ronald Sumida, and Michael E. Phelps. "PETT Imaging and Instrumentation." Journal of Nuclear Medicine Technology. Vol. 18, No. 1, March 1990. 5-13.

2. Jaszczak, Ronald J. and R. Edward Coleman. "Single Photon Emission Computed Tomography (SPECT) Principles and Instrumentation." Investigative Radiology, Vol. 20, No. 9, December 1985. 897-909.

3. Kuni, Christopher C. 1988. Introduction to Computers and Digital Processing in Medical Imaging. Year Book Medical Publishing, Inc., Chicago, IL. 75-96.

4. Sandler, Martin P., James A. Patton, Max I. Shaff, Thomas A. Powers and C. Leon Partain. 1989. Correlative Imaging. Williams \& Wilkins, Baltimore, MD. 3-30, 6392.

5. Sider, Lee (Editor). 1986. Introduction to Diagnostic Imaging. Churchill Livingstone Inc., New York, NY. 31-36.

6. Sochurek, Howard. "Medicine's New Vision." National Geographic, Vol.171, No. 1, January 1987. 34-41. 
7. Swenberg, Charles E. and James J. Conklin. 1988. Imaging Techniques in Biology and Medicine. Academic Press Inc., Ne York, NY. 78-109, 168-210, 263-299.

8. Tuinter, Suzanne. "Interior Journeys." Research News (Univ, of MI Div, of Res. Dev. and Admin.), Vol. 39, No.9-10, Sept. - Oct. 1988, 2-6.

9. The U.S. Diagnostic Imaging Industry (Industry Study developed for Hambrecht \& Quist) September 1982. 35-40.

\section{Magnetic Resonance Imaging}

1. Curry, Thomas S. III, James E. Dowdey, Robert C. Murray, Christensen's Physics of Diagnostic Radiology. Fourth Edition. Lea \& Febiger, Philadelphia, PA. 432-469, 470-504.

2. Kuni, Christopher C. 1988. Introduction to Computers and Digital Processing in Medical Imaging. Year Book Medical Publishers, Inc., Chicago, IL. 99-111.

3. Sandler, Martin P., James A. Patton, Max I. Shaff, Thomas A. Powers and C. Leon Partain. 1989. Correlative Imaging, Williams \& Wilkins, Baltimore, MD. 93-103.

4. Sider, Lee (Editor), 1986. Introduction to Diagnostic Imaging. Churchill Livingstone Inc., New York, NYY, 36-38.

5. Sochurek, Howard. "Medicine's New Vision." National Geographic, Vol.171, No. 1, January 1987. 12-23.

6. Swenberg, Charles E. and James J. Conklin (Editors). 1988. Imaging Techniques in Biology and Medicine. Academic Press Inc., New York, NY. 301-354.

7. Tainter, Suzanne. "Interior Journeys", Research News (Univ. of MI Div, of Res. Dev. and Admin.), Vol. 39, No. 9-10, Sept. - Oct. 1988. 5-11.

8. The U.S. Diagnostic Imaging Industry. (Industry Study developed for Hambrecht \& Quist) September 1982. 30-34. 


\section{Key to Imaging Modalities Tables}

The following tables (see next section) are a "ready reference" compilation of the survey sheets found after the description of each modality. These two tables should provide a quick, comprehensive view of the imaging modalities covered in this report. Please note that all answers are subject to the judgement of the health personnel interviewed.

For the sake of space and convenience, some of the information presented on these tables has been abbreviated. The following key should aid comprehension.

\section{FORM OF IMAGE \\ SPECTRUM}

PLANAR

TOMO

$3-D$
$=\mathrm{A}$ spectral representation of the chemical makeup of the body.

$=$ A two-dimensional planar projection of an area.

= A longitudinal-axis tomographic planar "slice" of the body.

$=$ A three dimensional image obtained by the "stacking" of tomographic slices.

\section{TEMPORAL RESOLUTION}

The length of time needed to gather the information necessary to construct the image.

\section{ELEMENTAL RESOLUTION}

Indicates whether the technique provides any information about the elemental composition of the tissues being imaged.

\section{INVASIVE/NONINVASIVE}

An invasive technique is, for our purposes, one which requires operative procedures or penetration. Surgery and catheterization are, by this definition, invasive. On the other hand, the ingestion or injection of foreign substances or exposure to ionizing radiation are not considered invasive although these procedures are mentioned on the survey sheets of each modality if applicable.

\section{IN/OUTPATIENT}

Indicates whether the procedure itself requires patient hospitalization.

\section{MORTALITY/MORBIDITY}

Specific statistics are indicated wherever possible. If exact information is not readily available, a general qualification, subject to the judgement of those persons interviewed, has been supplied. 


\section{MATURITY}

Subject to qualification by the persons interviewed. More specific information has been supplied on the survey sheets of each modality.

\section{AVAILABILITY}

Indicative of the general accessibility of the technique.

$R A R E$

= Very few such facilities are available for clinical use (if any clinical use).

MODERATE

$=$ The technique is clinically available but such facilities are not found in the majority of hospitals.

COMMON

$=$ The technique is both clinically available and facilities are found in the majority of hospitals.

More specific information regarding the availability of each technique has been supplied on the survey sheets of each modality.

\section{UTILITY}

Each technique has been qualified as being either RESEARCH or CLINICAL. This is indicative of the major use of the technique at present. 
VII. Tables

$-81-$ 


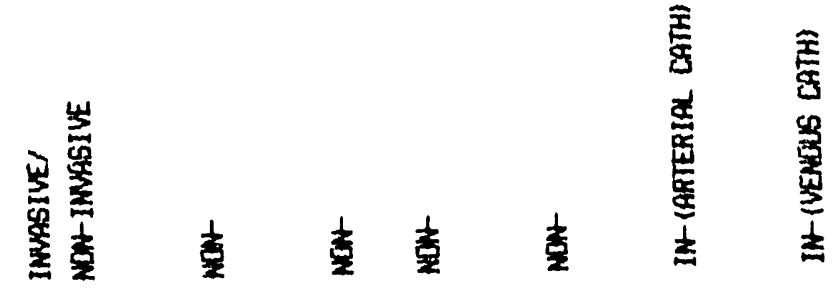

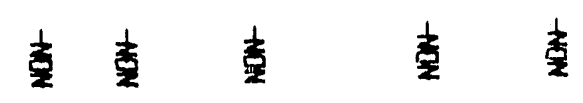

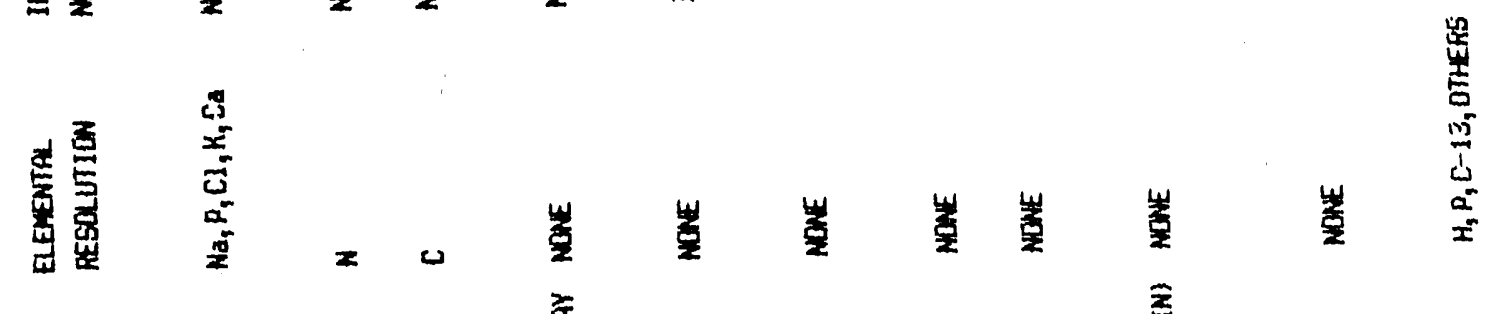

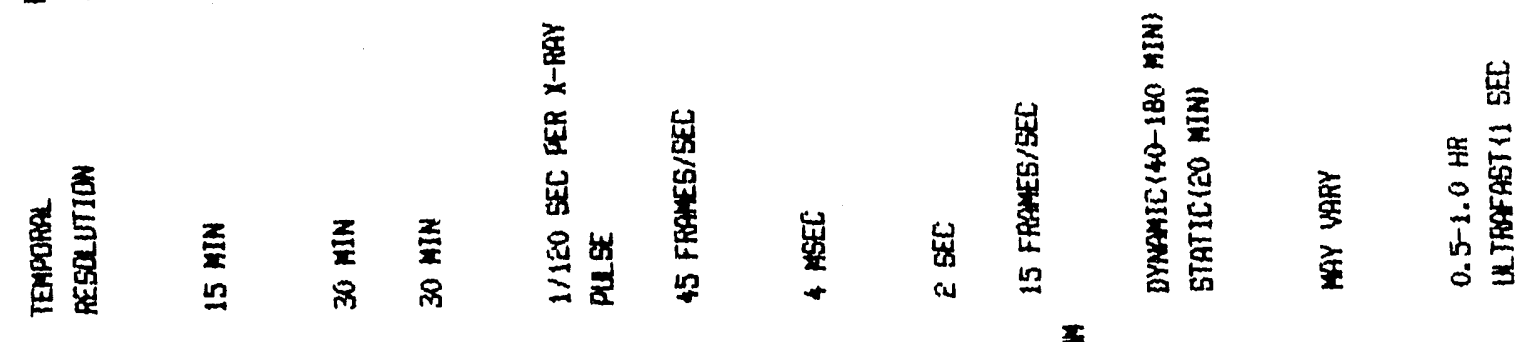

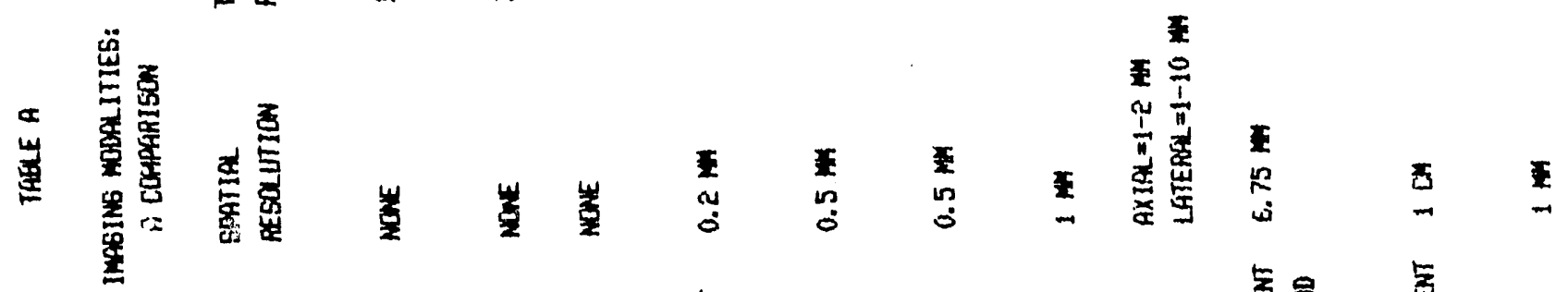

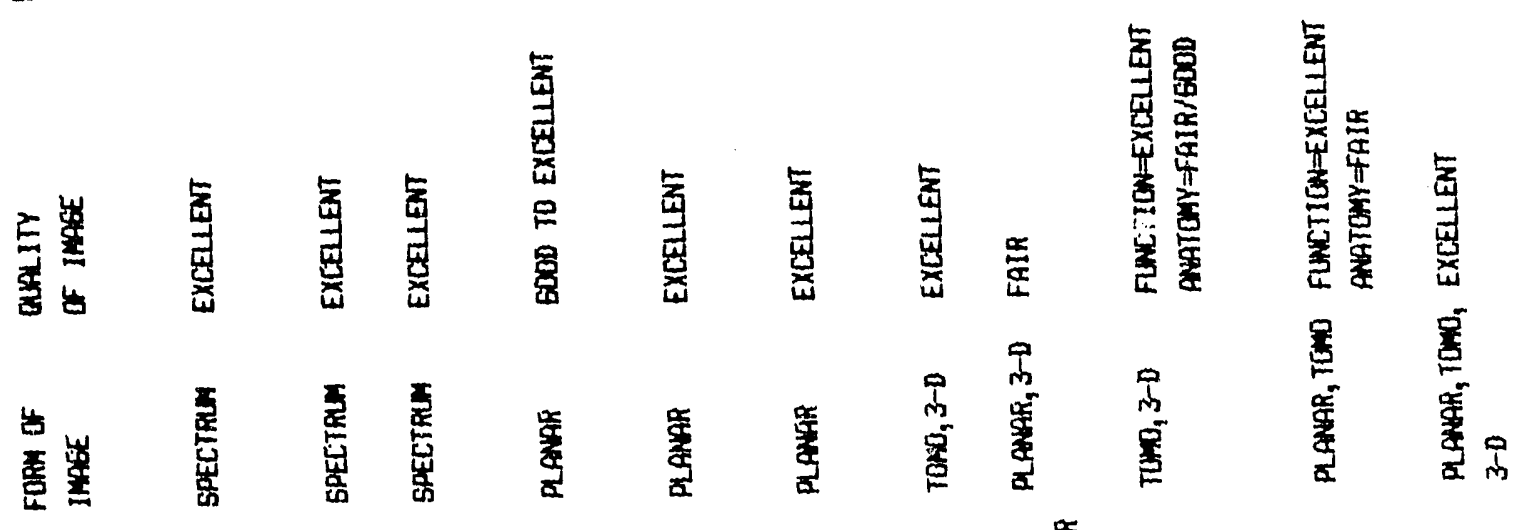

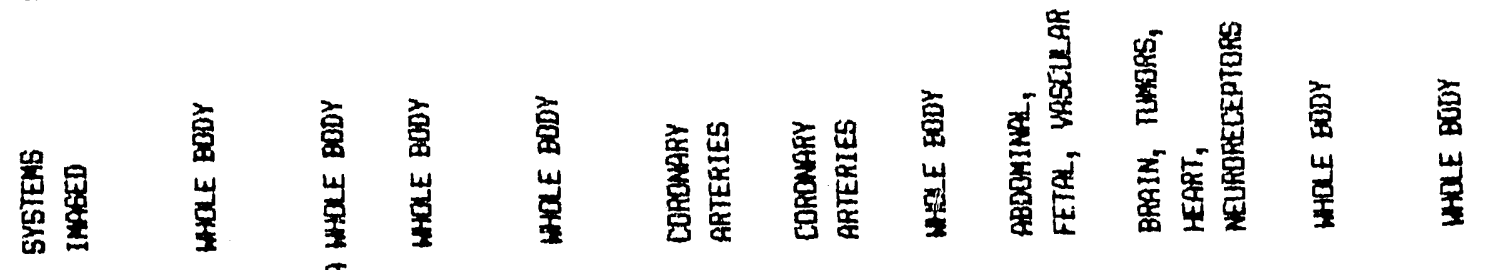

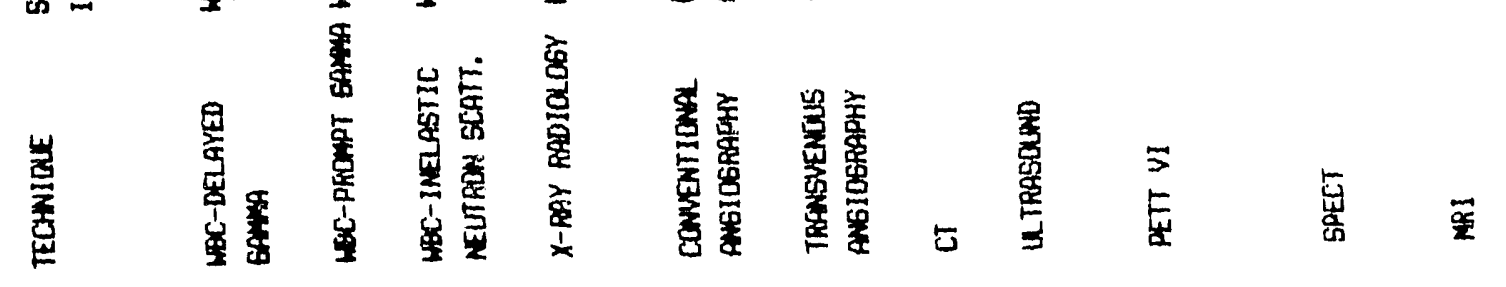


$-84-$ 


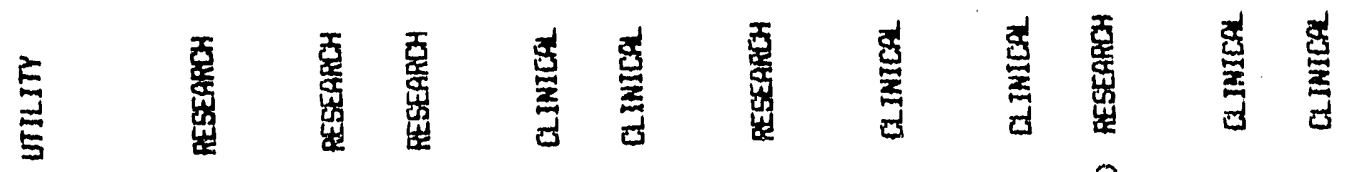

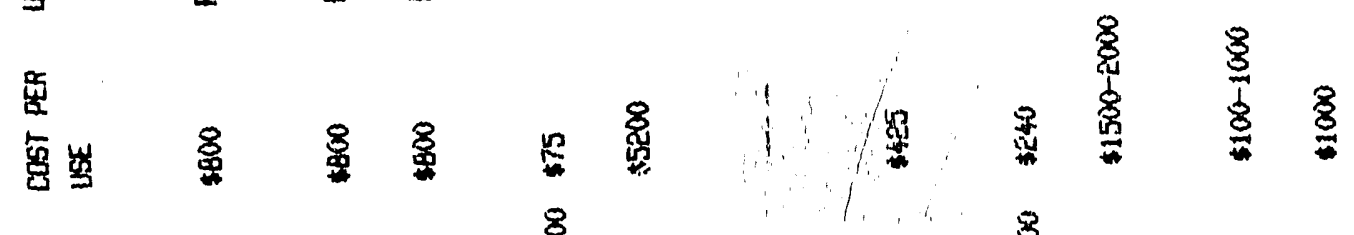

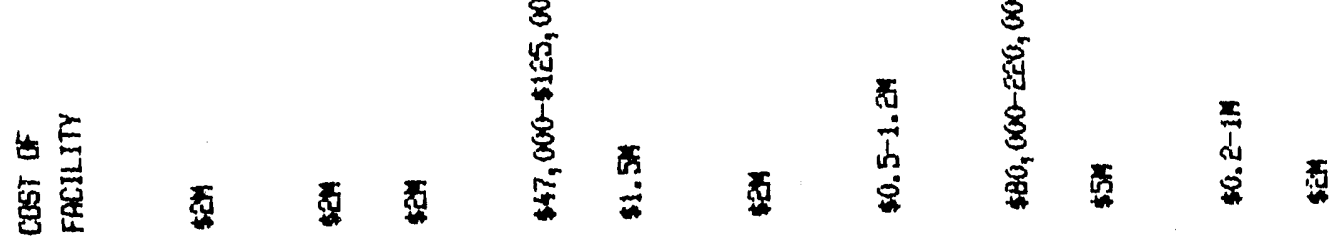

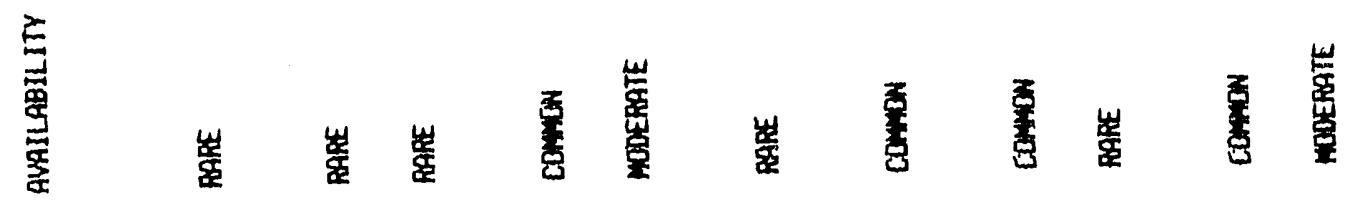

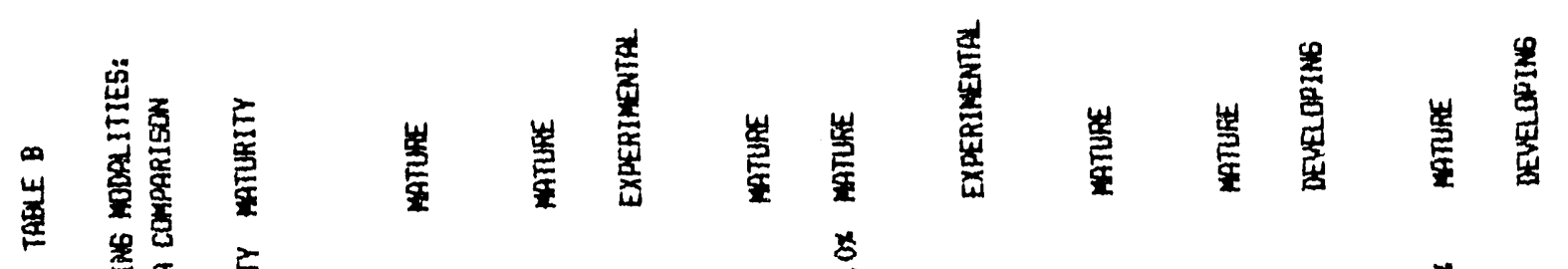

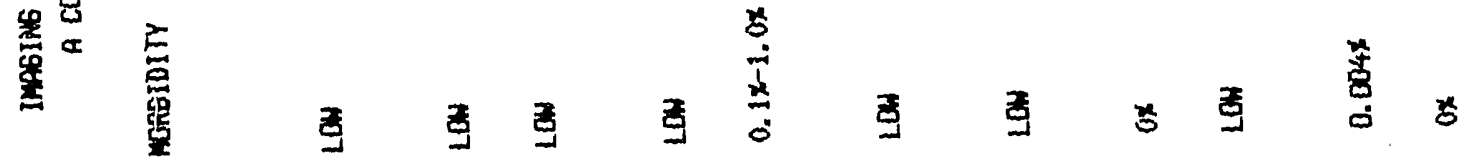

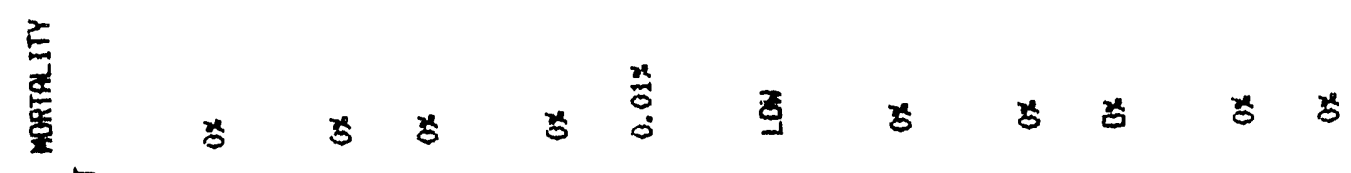

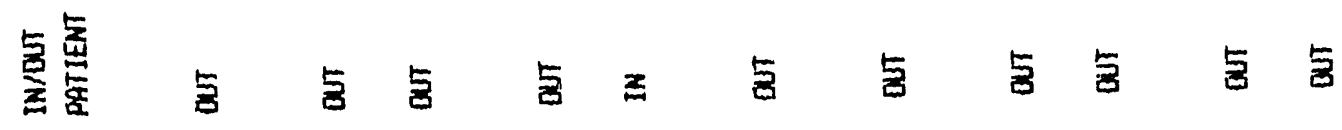

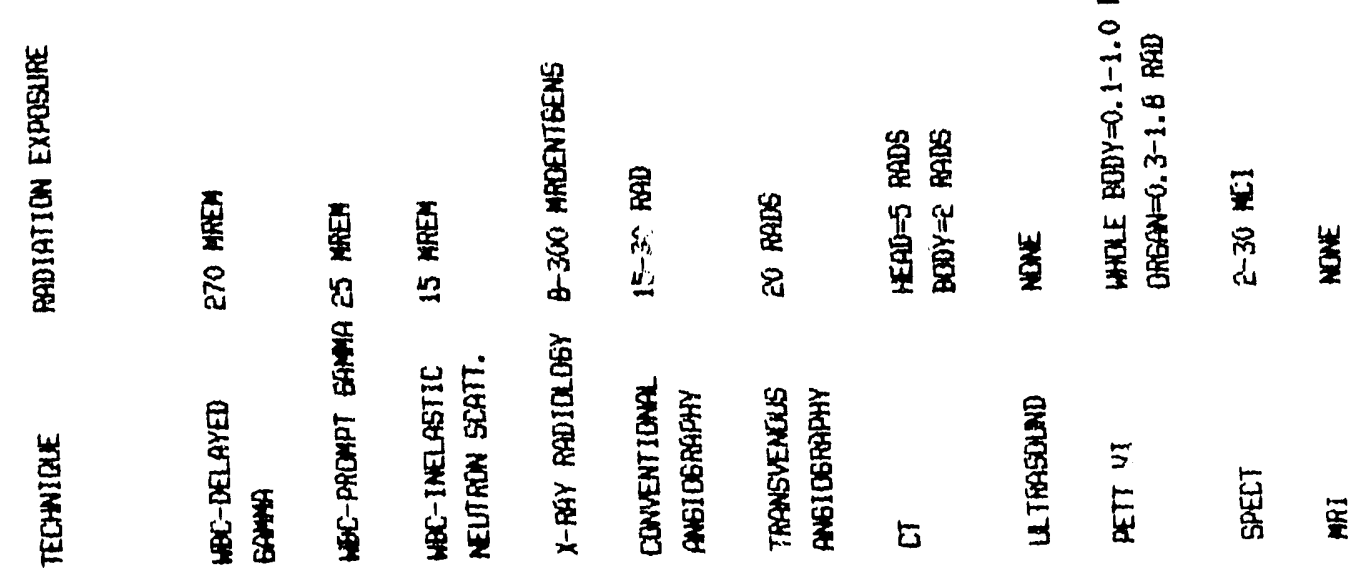



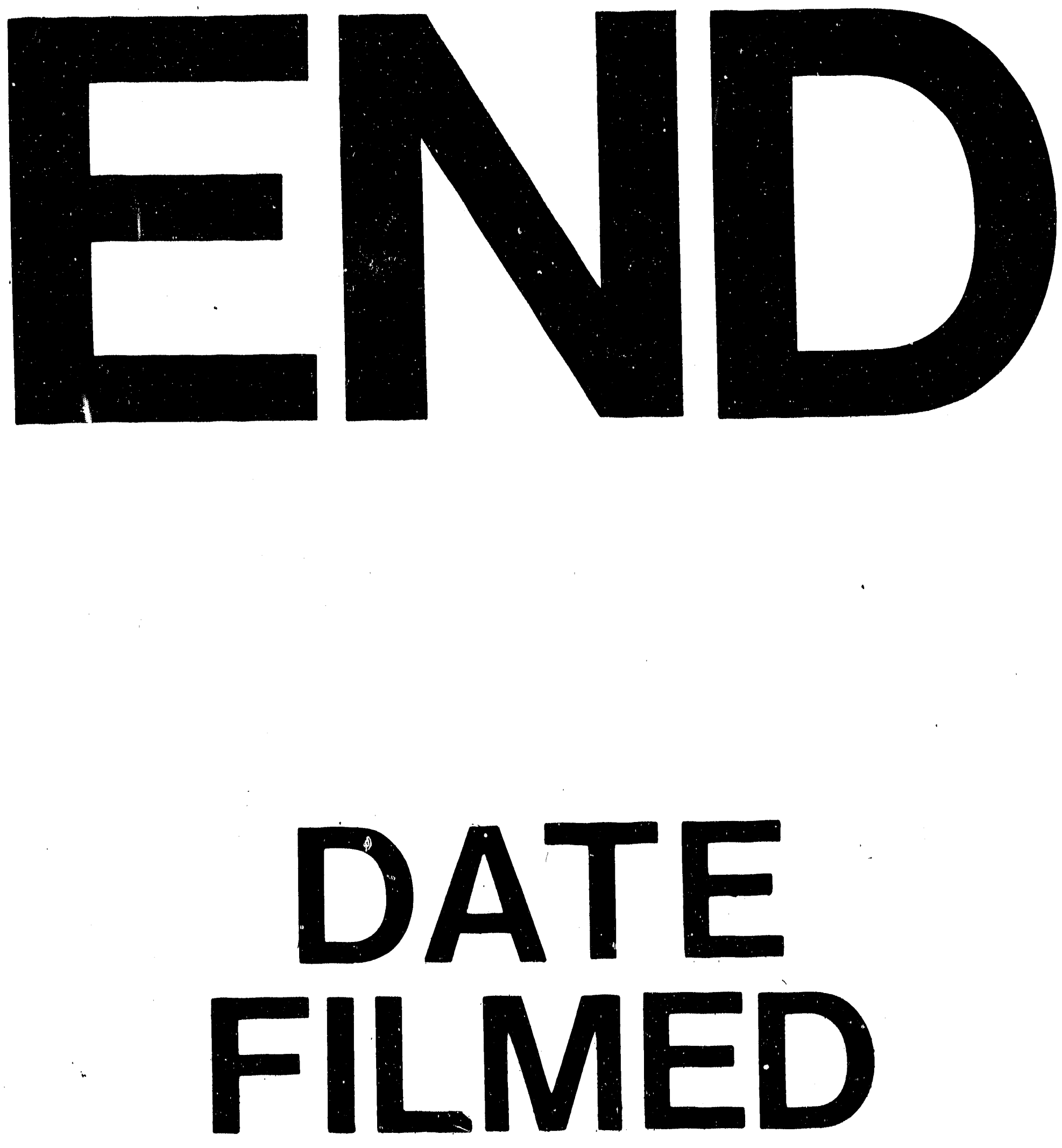

7

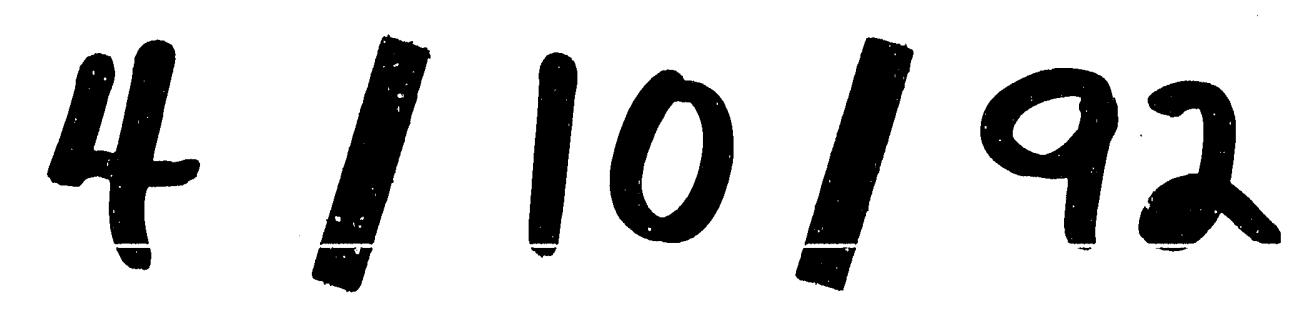


